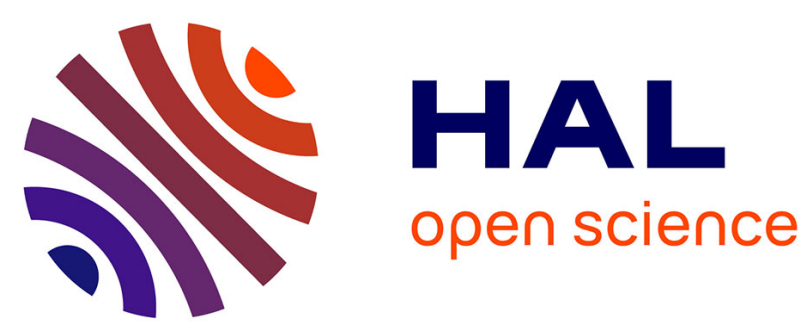

\title{
Dense water formation in the Gulf of Lions shelf: Impact of atmospheric interannual variability and climate change
}

Marine Herrmann, Claude Estournel, Michel Deque, Patrick Marsaleix, Florence Sevault, Samuel Somot

\section{To cite this version:}

Marine Herrmann, Claude Estournel, Michel Deque, Patrick Marsaleix, Florence Sevault, et al.. Dense water formation in the Gulf of Lions shelf: Impact of atmospheric interannual variability and climate change. Continental Shelf Research, 2008, 28 (15), pp.2092-2112. 10.1016/j.csr.2008.03.003 . hal02110205

\section{HAL Id: hal-02110205 \\ https://hal.science/hal-02110205}

Submitted on 10 Aug 2021

HAL is a multi-disciplinary open access archive for the deposit and dissemination of scientific research documents, whether they are published or not. The documents may come from teaching and research institutions in France or abroad, or from public or private research centers.
L'archive ouverte pluridisciplinaire HAL, est destinée au dépôt et à la diffusion de documents scientifiques de niveau recherche, publiés ou non, émanant des établissements d'enseignement et de recherche français ou étrangers, des laboratoires publics ou privés. 


\title{
Dense water formation in the Gulf of Lions shelf: Impact of atmospheric interannual variability and climate change
}

\author{
Marine Herrmann ${ }^{a, *}$, Claude Estournel ${ }^{a}$, Michel Déqué ${ }^{b}$, Patrick Marsaleix ${ }^{a}$, \\ Florence Sevault ${ }^{\mathrm{b}}$, Samuel Somot ${ }^{\mathrm{b}}$ \\ a Laboratoire d'Aérologie, Université de Toulouse, CNRS, 14 av. Edouard Belin, F-31400 Toulouse, France ${ }^{\text {b }}$ \\ Météo-France/CNRM, 42 av. Gaspard Coriolis, 31057 Toulouse Cedex, France
}

\begin{abstract}
Dense water formed over the continental shelf and cascading down the slope is responsible for shelfslope exchanges in many parts of the world ocean, and transports large amounts of sediment and organic matter into the deep ocean. Here we perform numerical modeling experiments to investigate the impact of atmospheric interannual variability and climate change on dense water formation over the Gulf of Lions shelf, in the Northwestern Mediterranean Sea. Results obtained for a 140 years eddy-permitting simulation (1960-2100) performed over the whole Mediterranean Sea under IPCC A2 scenario forcings are used to force a regional eddy-resolving model of the Northwestern Mediterranean Sea.

For the years selected in the present period, the quantity of dense water formed over and exported from the shelf is well correlated with atmospheric conditions, and dense water cascading is in agreement with available observations. During years colder than the average, most of the dense water formed over the shelf sinks into the deep ocean by cascading. During warmer years, dense water is mainly consumed by mixing with lighter surrounding water, and only a small quantity escapes the shelf, flowing along the coast without sinking.

For the years selected in the future period, dense water formation over the shelf is strongly reduced, due to the stronger stratification of the water column. Most of the dense water formed is consumed over the shelf by mixing. A very small part escapes the shelf, flowing mainly in the surface layer: cascading practically disappears.

The extrapolation of the results obtained for the selected years to the whole present and future periods suggests that volumes of dense water annually formed on the shelf, exported and cascading from the shelf are reduced by, respectively, 50\%, 90\% and 90\% between the 20th century and the end of the 21st century. Uncertainties regarding our results are evaluated: the uncertainty due to the choice of the atmospheric forcing model is the most important, however, a decrease of cascading of at least $60 \%$ for the end of the 21 st century compared to the present climate is obtained for every atmospheric model examined.
\end{abstract}

\section{Introduction}

In some parts of the world ocean coastal regions, winter atmospheric conditions induce episodic formation over the shelf of water of greater density than adjacent waters over the slope (Shapiro and Hill, 1997; Ivanov et al., 2004). This water cascades down the shelf-open ocean slope, transporting irreversibly large amounts of sediment and organic matter into the deep ocean, thus contributing to deep ocean carbon storage. Since it is strongly

\footnotetext{
* Corresponding author. Tel.: +33561332779.

E-mail address: marine.herrmann@aero.obs-mip.fr (M. Herrmann).
}

driven by atmospheric conditions, dense water (DW) cascading process shows a high interannual variability (Huthnance, 1995).

Due to its relative ease of access, the Gulf of Lions shelf, in the Mediterranean Sea, is particularly appropriate to study DW cascading. Several cascading events were observed during the last decades in this region (Béthoux et al., 2002; Durrieu de Madron et al., 2005; Canals et al., 2006), where the shelf-open ocean slope is cut by several canyons that funnel DW cascading down the slope. Due to the presence of the Rhône river, continental input and biological productivity over the Gulf of Lions shelf are high. DW cascading contributes importantly to the transport of this sediment and organic matter into the deep ocean, therefore affecting geological characteristics and deep ecosystems 
functioning in this area (Monaco et al., 1990; Palanques et al., 2006; Gaudin et al., 2006; Heussner et al., 2006; Canals et al., 2006). Due to its intermittent character, cascading is difficult to observe and its contribution to shelf-deep ocean exchanges is difficult to quantify. However, analyzing series of sediment concentration, hydrological characteristics and current velocity provided by moorings equipped with current metres and sediment traps and installed in the canyons of the Gulf of Lions, the experimentators cited above estimated volumes of DW water and organic matter transported along the slope for winters 1998-1999 and 2004-2005 and for the 1993-2001 period. The first experimental study aimed at describing spatial, seasonal and interannual variability of the flux intensity of particulate matter was performed by Heussner et al. (2006). They concluded that DW cascading may be predominantly responsible for the interannual variability of the transfer of particulate matter. However, they underlined that causal relationships between the forcings and this variability could not be demonstrated by the time series analyzed, and that further studies of such relationships are necessary.

Beside these observations, numerical studies of observed cascading events were performed by Dufau-Julliand et al. (2004) and Ulses et al. (2008) for winters 1998-1999 and 2003-2004 using the numerical circulation model SYMPHONIE. Those studies demonstrated the ability of this model to reproduce correctly DW formation and cascading characteristics, in particular the DW formation areas, the cascading velocities, the volume of cascading water and the intermittence of the cascading process. SYMPHONIE can therefore be used now to examine the interannual variability of the cascading process and to provide further quantification of integrated DW fluxes. This would help to complete the observational study performed by Heussner et al. (2006) and to provide a first answer to the issues raised by these authors. This constitutes the first objective of the present study.

Somot et al. (2006) showed that climate change could reduce open-ocean convection and associated DW formation in the Mediterranean Sea. Given the high sensitivity of DW cascading to meteorological conditions, one can expect this process to be influenced by climate change. A numerical model is used here to provide a first answer to this question, to raise the important issues that need to be studied and to evaluate the uncertainties of climate change impact.

We perform a three-dimensional numerical study in order to investigate the effects of atmospheric interannual variability and climate change on DW formation over and export off the Gulf of Lions shelf. The modeling tools and strategy are presented in Section 2. In Section 3 we examine the effects of atmospheric interannual variability under present climate conditions by studying a group of selected years. Quantitative estimations of the volumes of DW formed over the shelf then exported and cascading, and of their interannual variability, are proposed and compared with available data. We also study the geographical characteristics of DW export and cascading. Impacts of climate change on these volumes and characteristics are examined and quantified for a group of selected years in Section 4, and explanations for these impacts are proposed. Results obtained in Sections 3 and 4 are extrapolated to the whole present and future periods in Section 5. Uncertainties regarding our results are presented in Section 6 .

\section{Tools and methods}

\subsection{Modeling strategy}

Somot et al. (2006) performed a 140-year (1960-2100) numerical study over the whole Mediterranean Sea to investigate the impact of climate change on the Mediterranean thermohaline circulation. For that, they used the $1 / 8^{\circ}$ resolution Oceanic Regional Circulation Model (ORCM) OPA, eddy-permitting in the NWMS. To force this model at the surface, air-sea fluxes were provided by a run performed with the high-resolution $(50 \mathrm{~km})$ Atmospheric Regional Climate Model (ARCM) ARPEGE-Climate over the 1960-2100 period (Gibelin and Déqué, 2003). Both the ARCM and the ORCM were forced by the results of a simulation performed with the low-resolution Atmosphere-Ocean General Circulation Model (AOGCM) ARPEGE-OPA. These simulations were divided into two periods. During the first period (1960-2000), the greenhouse gases and aerosols concentrations corresponded to the observed concentrations. During the second period (2000-2100), these concentrations increased following the IPCC A2 scenario (IPCC, 2001). Note that there was no data assimilation in the atmospheric simulations: they were realistic from a climatological point of view, but, due to the atmospheric chaotic behavior, a climate model year did not correspond to the actual year with the same number. For example, year number 1962 is just the third year of the simulation, and one should not expect this year to follow the chronology of the real year 1962. In the ORCM simulation, a surface relaxation toward the AOGCM sea surface temperature (SST), used to force the ARCM, ensured the consistency between surface heat fluxes coming from the ARCM and SST calculated by the ORCM. This term, equivalent to a heat flux, and called the relaxation heat flux in the following, was actually a first-order coupling between the ORCM SST and the atmosphere heat flux.

Somot et al. (2006) showed that climate change could reduce open-ocean convection and associated DW formation in the Mediterranean Sea main basins by the end of the 21st century. However, effects of climate change on regional and coastal processes like shelf DW formation were not examined. Herrmann et al. (2008) showed that $1 / 8^{\circ}$ resolution is not sufficient to simulate correctly the mesoscale processes involved in the NWMS circulation but that using an embedded eddy-resolving model enables to represent accurately such processes that play an important role in the fate of DW. Results of the ORCM and ARCM simulations are therefore used here to prescribe surface and lateral open boundary conditions for the regional eddy-resolving oceanic model described in Section 2.2, in order to study the impacts of atmospheric interannual variability and climate change on the DW formation and export over the Gulf of Lions shelf.

Due to technical constraints, it is not currently possible to perform a 140 -year numerical simulation with the regional eddyresolving oceanic model. The strategy adopted here is therefore to select a set of representative years for the 20th century (1961-1990, the "present period") and for the end of the 21st century (2071-2100, "the future period") in the 140-year simulation. We choose the 1961-1990 and 2071-2100 periods, long enough to ensure a large signal/noise ratio: the climate change signal will not be masked by the natural variability of the climate system. Since DW formation is strongly influenced by winter surface heat loss, we examine surface heat loss averaged over the coldest period, i.e. December-February, $H L_{D J F}$, and over the NWMS, for each year of the 30-year present and future periods of the ARCM simulation (Fig. 1). Note that $H L_{D J F}$ is in average stronger for the future period $\left(150 \mathrm{~W} \mathrm{~m}^{-2}\right)$ than for the present period $\left(135 \mathrm{~W} \mathrm{~m}^{-2}\right)$. Seven years are selected for each period, with winter heat loss distributed over the whole range of the heat loss values (see the histograms in Fig. 1): three years with strong heat loss ("cold years", C1, C2, C3), three years with weak heat loss ("warm years", W1, W2, W3) and an approximately average year (A1). The regional oceanic model is then used to perform 14 oneyear simulations over the NWMS, corresponding to the 14 selected years. Each simulation begins in September. 

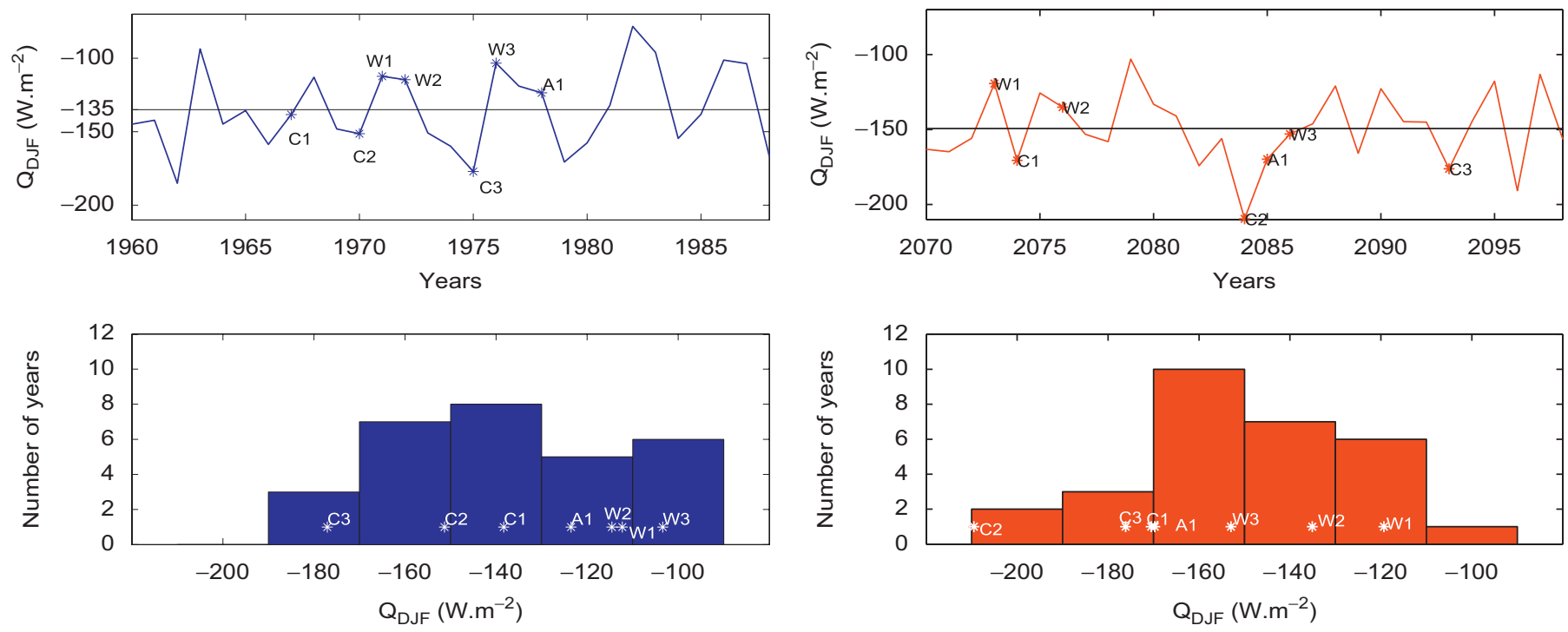

Fig. 1. Selection of representative years in the present (left) and future (right) periods. Top: winter heat flux averaged over the NWMS in the ARCM simulation, $Q_{D J F}=-H L_{D J F}$. The black line corresponds to the winter heat loss averaged over the whole period. Bottom: distribution of $Q_{D J F}$ in the ARCM simulation. Value of $Q_{D J F}$ for each selected year is marked by an asterisk and the corresponding year name.

\subsection{The numerical eddy-resolving regional oceanic model}

The three-dimensional primitive equation hydrostatic ocean model SYMPHONIE is described in detail in Marsaleix et al. (2006). The model configuration used here is the same as the one described in Herrmann et al. (2008). Previous studies showed that this model reproduces correctly the shelf DW formation in the Gulf of Lions (Dufau-Julliand et al., 2004; Ulses et al., 2008) and in the Gulf of Thermaikos (Estournel et al., 2005) as well as the opensea deep convection in the Northwestern Mediterranean Sea (Herrmann et al., 2008; Herrmann and Somot, 2008).

Due to the hydrostatic assumption, the model does not represent the convective processes that restore the stability in the real ocean when static instabilities develop. Therefore, to take those processes into account, a non-penetrative convective adjustment algorithm, as described by Madec et al. (1991), is used in case of unstable stratification. The use of a hydrostatic model could be questionable here since strong variations of current are likely to be found through the head of the DW plumes. Heggelund et al. (2004) showed that the shape of the DW plume head is quite sensitive to the choice of a hydrostatic or non-hydrostatic model, but that the thickness of the plume behind the head and the time required for the DW to reach the depth of buoyancy equilibrium are nearly the same in both cases. As far as we are more concerned with global issues than in the plume dynamics itself, the use of a hydrostatic model is therefore acceptable. Moreover, the computation of the non-hydrostatic pressure elliptic equation is quite expensive. For the same cost, the hydrostatic model has a better resolution and/or a larger domain and represents consequently better the background circulation that plays a significant role in the DW fate (Shapiro and Hill, 1997; Dufau-Julliand et al., 2004). Fig. 2 shows the modeled domain.

For each selected year, lateral boundary conditions for SYMPHONIE are provided at each time step by the timeinterpolated monthly averaged outputs of the corresponding year in the ORCM simulation performed by Somot et al. (2006). The ORCM simulation also provides the September initial conditions for each selected year. At the surface, the model is forced by daily air-sea fluxes extracted from the ARCM run: heat flux, water flux and wind stress. The value of the relaxation heat flux applied in the ORCM simulation is added to the ARCM heat flux. The freshwater discharge of the Rhône river is introduced as a lateral boundary condition, using the same values as Somot et al. (2006): the UNESCO RivDis database (Vörösmarty et al., 1996) provides climatological monthly values for the discharge during the present period. For the future period, they apply for each decade a constant multiplying factor to those climatological monthly values in order to modify the Rhône runoff accordingly to the ARCM simulation hydrological fluxes. The consistency of this forcing method was demonstrated in the process study performed by Herrmann et al. (2008) that showed that SYMPHONIE does not drift away from the ORCM.

\subsection{DW criteria}

In the following, the boundary between the shelf and the deep sea (SDS boundary) is defined using the $1000 \mathrm{~m}$ isobath that runs across the slope (see Fig. 2). It is then necessary to establish a consistent density criteria to distinguish DW formed over the shelf and crossing this boundary from the surrounding water. Since cascading DW has variable density characteristics from one year to another (Béthoux et al., 2002), it would not be adequate to use a unique value. Moreover, as we will see in the following, water density over the Gulf of Lions shelf and along the SDS boundary changes a lot between the end of the 20th and 21st centuries (Fig. 3). Examining the density over the vertical section formed by the SDS boundary, DW cascading can be identified when flows of water of higher density than the surrounding water flow across the boundary, as observed on a vertical section of the density in the Cap Creus (CC) canyon during cascading events occurring during years $\mathrm{C} 2$ of the present and future period (Fig. 3 ). The density criteria are therefore defined as $\rho_{\text {crit }}=\rho_{\text {bottom }}+\Delta \rho$. $\rho_{\text {bottom }}$ is the mean density at the bottom of the SDS boundary averaged over the month preceding potential cascading events, i.e. December. $\Delta \rho$ is a constant density anomaly corresponding to the difference between the DW that escapes the SDS boundary and the water present at the bottom of this boundary. The value of $\Delta \rho$, here $0.03 \mathrm{~kg} \mathrm{~m}^{-3}$, is determined by examining the density over the boundary when cascading occurs (see for example Fig. 3). Moreover, this value seems to give realistic results when estimating the quantity of DW cascading across the slope, as we 


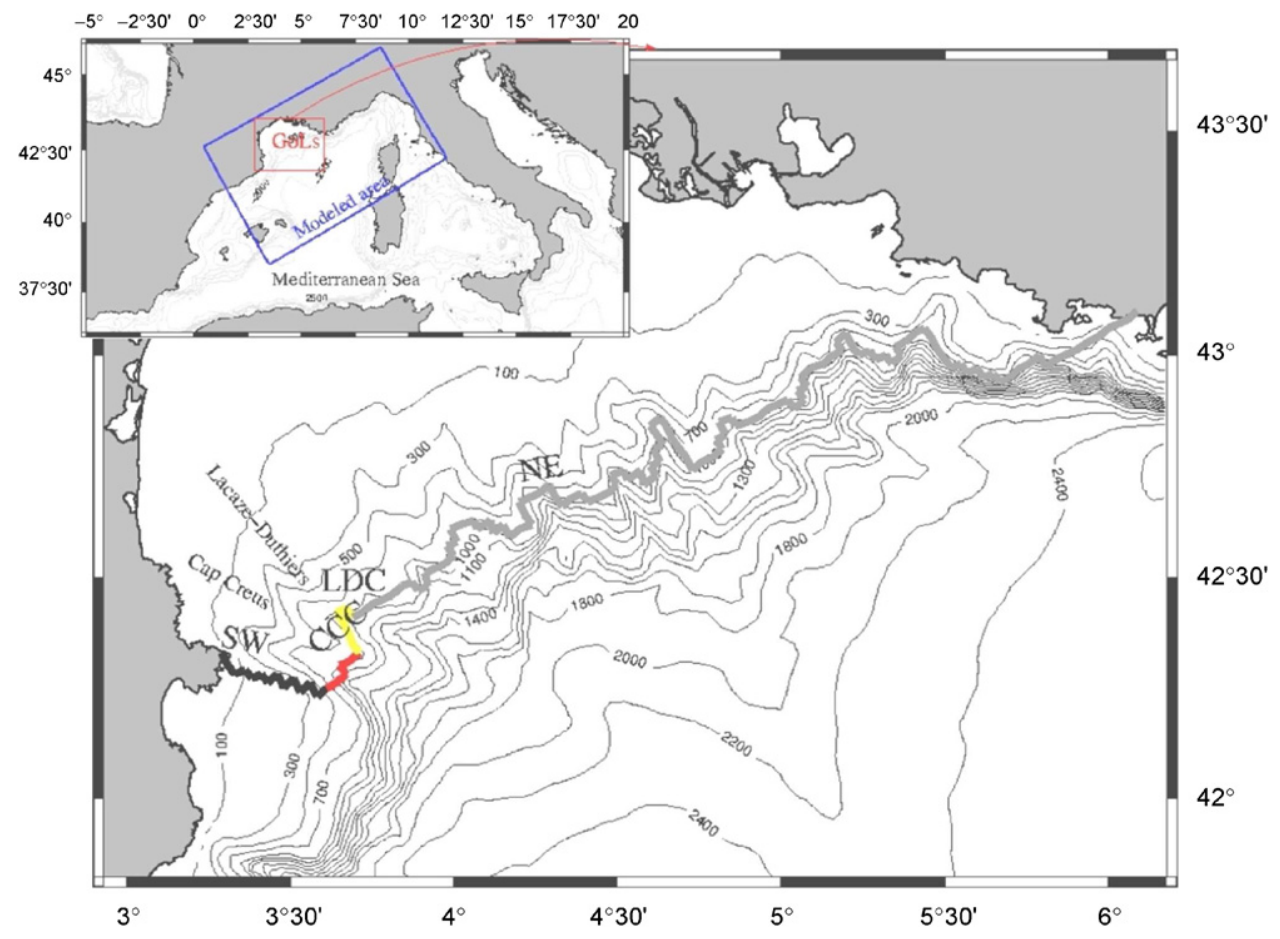

Fig. 2. Bathymetry of the modeled domain (unit: $\mathrm{m}$ ). The blue box in the small frame shows the boundaries of the area covered by the regional oceanic model SYMPHONIE. The red box correspond to the zoomed area for which the bathymetry is shown. The colored (black, red ...) line in the large frame represents the shelf-deep sea (SDS) boundary, with the colors corresponding to the portions detailed in Section 3.3 (black: Southwestern end, red: Cap Creus canyon, yellow: Lacaze-Duthiers canyon, grey: Northeastern end)
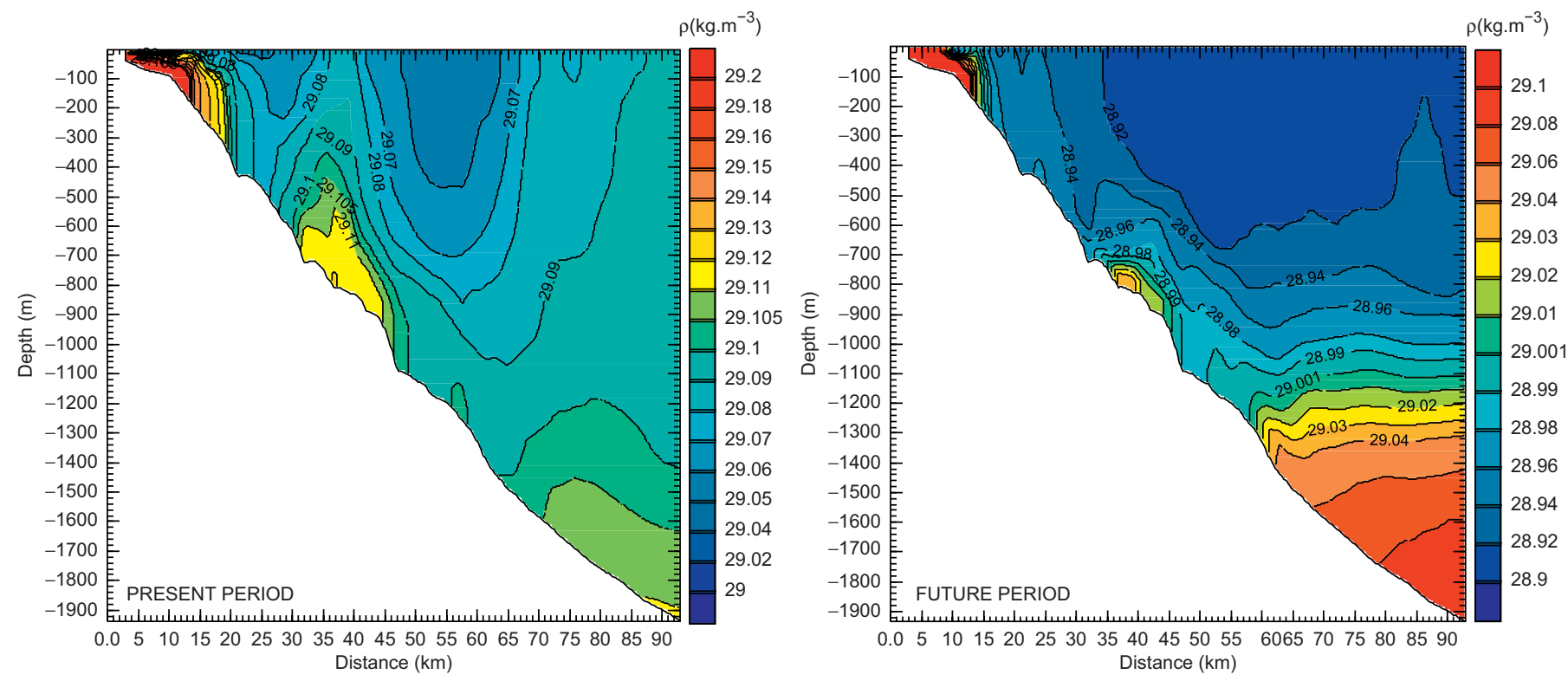

Fig. 3. Density $\left(\mathrm{kg} \mathrm{m}^{-3}\right)$ along the Cap Creus canyon during cascading events. Left: in the present period $\left(\mathrm{C} 2, \rho_{\text {bottom }}=29.075 \mathrm{~kg} \mathrm{~m}{ }^{-3}, \rho_{\text {crit }}=29.105 \mathrm{~kg} \mathrm{~m}{ }^{-3}\right)$. Right: in the future period $\left(\mathrm{C} 2, \rho_{\text {bottom }}=28.701 \mathrm{~kg} \mathrm{~m}^{-3}, \rho_{\text {crit }}=29.001 \mathrm{~kg} \mathrm{~m}^{-3}\right)$.

will see in Section 3.4. The obtained criteria are presented in Table 1. A sensitivity analysis to these criteria is presented in Section 6 .

\section{Impact of interannual variability on the DW formation and transport under present-day climate conditions}

In this section, we investigate the effects of interannual variability on DW formation over and export from the Gulf of Lions shelf. For this purpose, we compare the results obtained for the seven years selected in the present period. In the following, the region used to compute volumes or surfaces over the shelf is the region located northwest of the SDS boundary shown in Fig. 2. DW formation does not occur before December, we therefore examine the evolution of the DW formed over the shelf after December 1st of each year. DW can be formed or consumed by surface fluxes, stored over the shelf, formed or eliminated by mixing or by advection across the SDS boundary, following the conservation 
Table 1

Density of water over the shelf during the DW formation period (20/12-01/04) for each selected year of the present and future periods, average $(\bar{\rho})$ and standard deviation $\left(\sigma_{\rho}\right)$

\begin{tabular}{|c|c|c|c|c|c|c|c|c|c|}
\hline & $\mathrm{C} 1$ & $\mathrm{C} 2$ & $\mathrm{C} 3$ & $\mathrm{~A} 1$ & W1 & W2 & W3 & $\bar{\rho}$ & $\sigma_{\rho}$ \\
\hline \multicolumn{10}{|c|}{ Present period } \\
\hline$\rho_{\text {crit }}$ & 29.103 & 29.105 & 29.110 & 29.108 & 29.107 & 29.105 & 29.112 & 29.107 & 0.003 \\
\hline$\rho_{G D L, \max }$ & 29.07 & 29.07 & 29.08 & 28.99 & 28.96 & 28.91 & 29.00 & 29.01 & 0.06 \\
\hline$\rho_{L W, \max }$ & 29.02 & 29.03 & 29.03 & 28.97 & 28.94 & 28.91 & 28.97 & 28.98 & 0.05 \\
\hline \multicolumn{10}{|c|}{ Future period } \\
\hline$\rho_{\text {crit }}$ & 28.993 & 29.001 & 28.985 & 28.991 & 29.001 & 28.996 & 29.992 & 28.994 & 0.006 \\
\hline$\rho_{G D L, \max }$ & 28.90 & 28.93 & 28.73 & 28.90 & 28.86 & 28.67 & 28.76 & 28.82 & 0.10 \\
\hline$\rho_{L W, \max }$ & 28.88 & 28.87 & 28.72 & 28.85 & 28.84 & 28.67 & 28.76 & 28.80 & 0.08 \\
\hline
\end{tabular}

Dense water criteria $\rho_{\text {crit }}$, temporal maximum of the water density averaged over the shelf, $\rho_{G D L, \text { max }}$, and temporal maximum of the mean density of light water surrounding the DW (corresponding to $\rho<\rho_{\text {crit }}$ ), $\rho_{L W, \max }$. Unit: $\mathrm{kg} \mathrm{m}^{-3}$.

equation:

$V=$ Surf + Mix + Trans

where Surf is the volume of DW formed at the surface, $V$ is the stored volume, Mix is the volume formed by mixing and Trans is the net volume transported across the boundary into the shelf. Positive (resp. negative) values for Surf, Mix and Trans correspond to production (resp. consumption) of DW over the shelf. For each year, the volume $\Delta$ Surf of DW produced at the surface by the atmospheric fluxes during the time $\Delta t$ is computed using the Walin (1982) method as done by Tziperman (1986) and Speer and Tziperman (1992): this volume corresponds to the volume of water that crosses the isopycnal $\rho_{\text {crit }}$ due to the surface fluxes. It can be evaluated using the Speer and Tziperman (1992) formula:

$\Delta$ Surf $=\frac{-\rho_{0}}{g \delta \rho} \sum_{(x, y) / \rho(x, y) \in\left[\rho_{c r i t} \pm(1 / 2) \delta \rho\right]} B \Delta x \Delta y \Delta t$

with $g=9.81 \mathrm{~m} \mathrm{~s}^{-2}$ the gravitational acceleration, $\rho_{0}=$ $1020 \mathrm{~kg} \mathrm{~m}^{-3}$ the density reference, $\Delta x=\Delta y=3000 \mathrm{~m}$ the model resolution and $\delta \rho=0.01 \mathrm{~kg} \mathrm{~m}^{-3}$. As explained by those authors, the value of $\delta \rho$ is a compromise: it should be small enough so that one does not include a too large range of density values, but large enough not to exclude grid points containing DW because of the averaging induced by the model resolution. We performed sensitivity test to $\delta \rho$ and obtained a $6 \%$ range of variation for the volume of DW formed when $\delta \rho \in[0.002 ; 0.05] \mathrm{kg} \mathrm{m}^{-3}: \delta \rho$ is not a significant source of uncertainty in this study. The buoyancy flux $B$ is given by

$B=g \cdot\left(\frac{\alpha \cdot Q}{\rho_{0} \cdot C_{p}}-\beta . S S S .(E-P)\right)$

where $Q=-H L$ is the mean heat flux during $\Delta t$, SSS is the sea surface salinity, $E-P$ is the net water loss, $C_{p}=4000 \mathrm{~J} \mathrm{~kg}^{-1} \mathrm{~K}^{-1}$ is the specific heat and $\alpha=2 \times 10^{-4} \mathrm{~K}^{-1}$ and $\beta=7.6 \times 10^{-4}$ are the thermal and saline expansion coefficients. Integrating Eq. (2) between December 1st and $t$, we obtain Surf, the total volume of DW formed at the surface between December 1st and $t$. We then compute the volume of DW stored over the shelf, $V$, and the cumulated net import of DW across the shelf-slope boundary SDS between December $1 \mathrm{st}$ and $t$, Trans. The cumulated volume produced by mixing, Mix, is obtained using the conservation equation (1). Results are presented in Fig. 4.

Differences of the density of water masses over the shelf between the selected years are much larger than differences of density criteria (Table 1). In the following, it is therefore legitimate to compare densities among the different years instead of comparing differences between the density and the criteria, as we should rigorously do, to explain the observed differences.

\subsection{Formation of $D W$ over the shelf}

DW formation occurs mainly between end of December and beginning of April (Fig. 4b), in agreement with observations made by Palanques et al. (2006). It is mainly due to surface fluxes, and for some years, to mixing (Fig. 4c).

DW surface formation shows a strong interannual variability, with a factor of 17 between the highest (C2) and lowest (W2) yearly integrated surface formation. Since surface formation occurs during strong heat loss events (Fig. 4a,b), this variability is mainly related to the atmospheric variability. We indeed obtain a 0.85 correlation factor between the total quantity of DW formed at the surface between December 1st and the end of the formation period, Surf ${ }_{T O T}$, and the mean heat loss over the NWMS between December and March, i.e. when surface formation occurs, $H L_{D J F M}$.

The water density averaged over the shelf, maximum during the surface formation period, is higher for the cold years than for the warm years due to stronger heat losses (Table 1). Consequently, during cold winters, the mixing of large amounts of newly formed DW with the surrounding water, itself denser than during mild winters (Table 1), produces DW (Fig. 4c). On the contrary, during warm winters, the mixing process concerns low quantities of DW and surrounding waters of low density, and results in the consumption of DW.

\subsection{Elimination of DW}

For every year, some of the DW formed at the surface is stored during the surface formation period (Fig. 4c). However, at the beginning of June, all the DW formed at the surface have been completely eliminated from the shelf. The elimination of DW also shows a strong interannual variability: DW can be consumed by mixing or/and by export, and to a lesser extent, by surface fluxes (Fig. 4a,c). For the cold years (resp. C1, C2, C3), the largest part of the DW formed at the surface and by mixing leaves the shelf by crossing the SDS boundary: total cumulated export is equal to, respectively, $64 \%, 84 \%$ and $61 \%$ of the total DW surface formation. On the contrary, for the average and warmer years (A1, W1, W2, W3), DW is completely eliminated by mixing. Two reasons explain this difference.

The first reason was explained in the previous section: due to the difference of water density between cold and warm years, mixing consumes DW during warm years, therefore reducing the volume available for export, whereas it produces DW during cold years. Moreover, the contrast between the DW and the surrounding water is reduced by mixing during the warm years, so that the gravity current, i.e. the cascading, resulting from this contrast is 
a

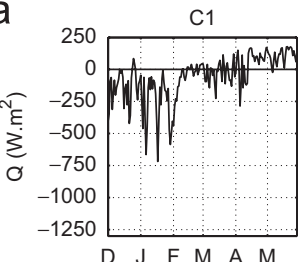

b
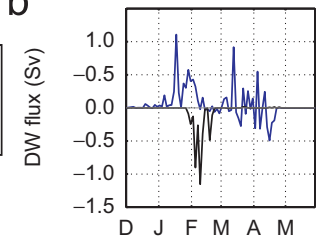

C
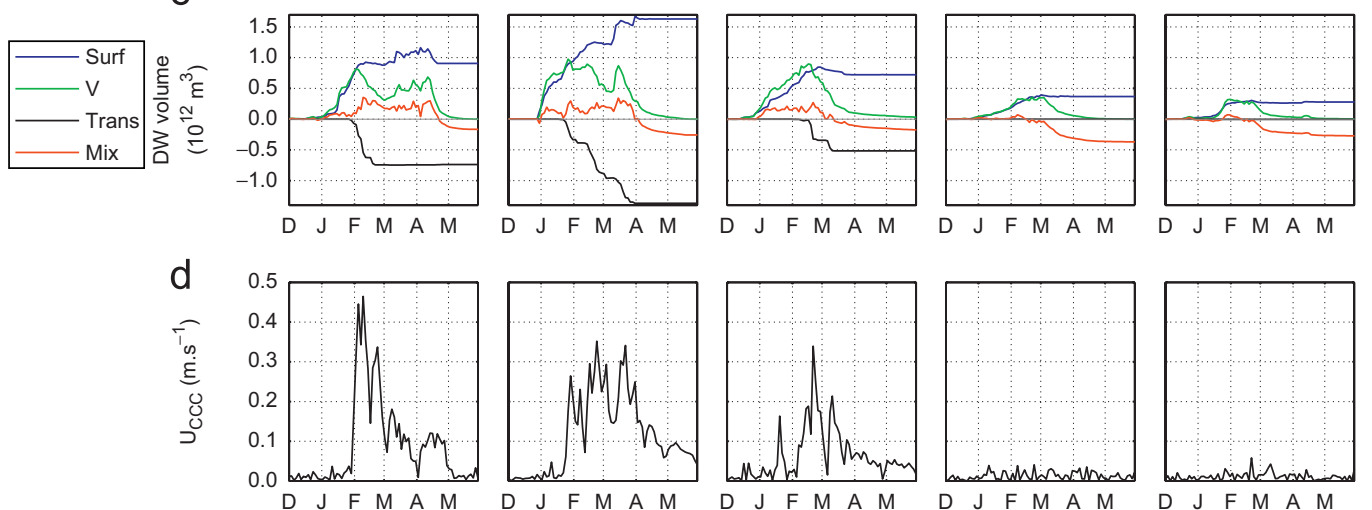

D J F M A M
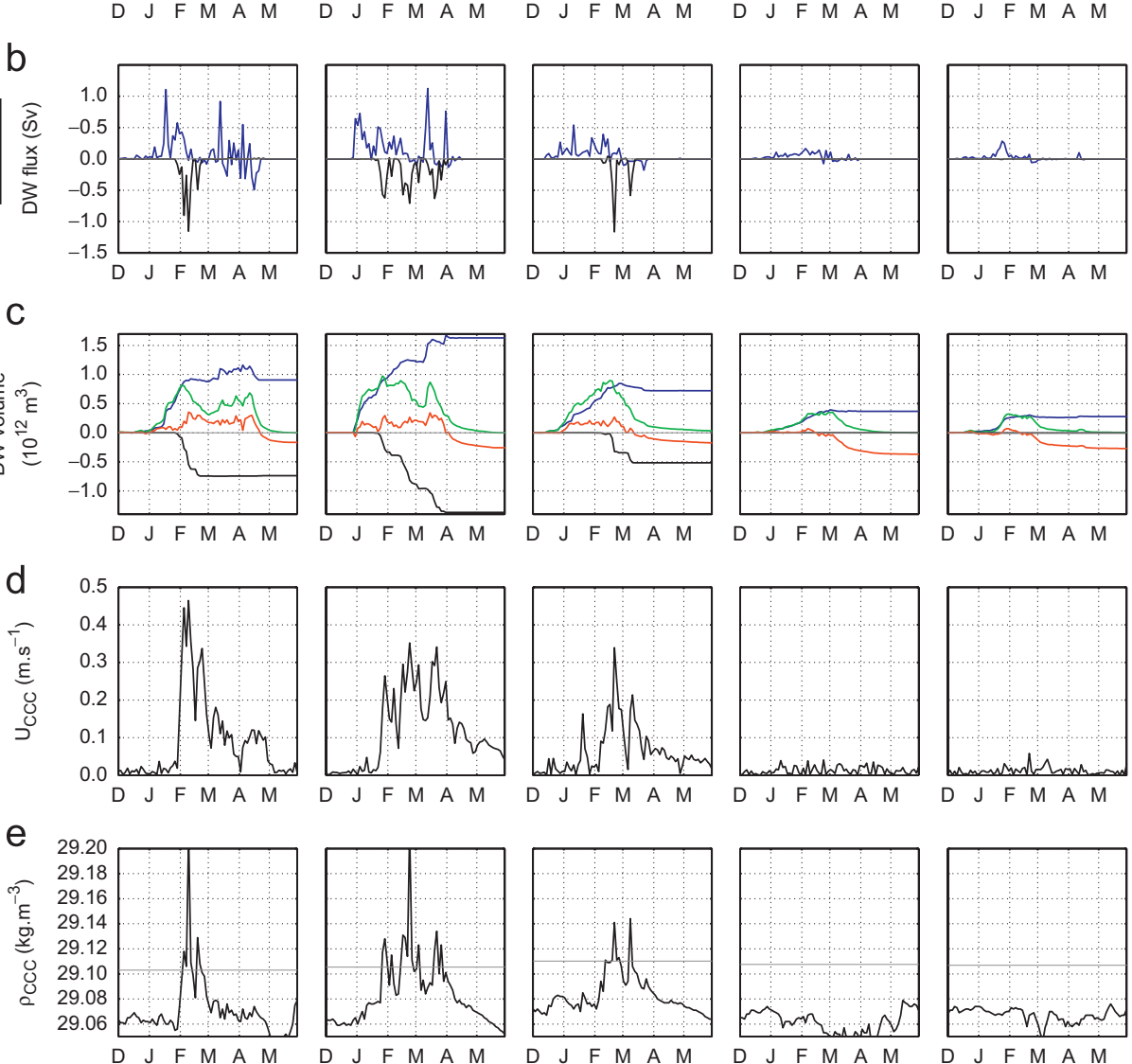
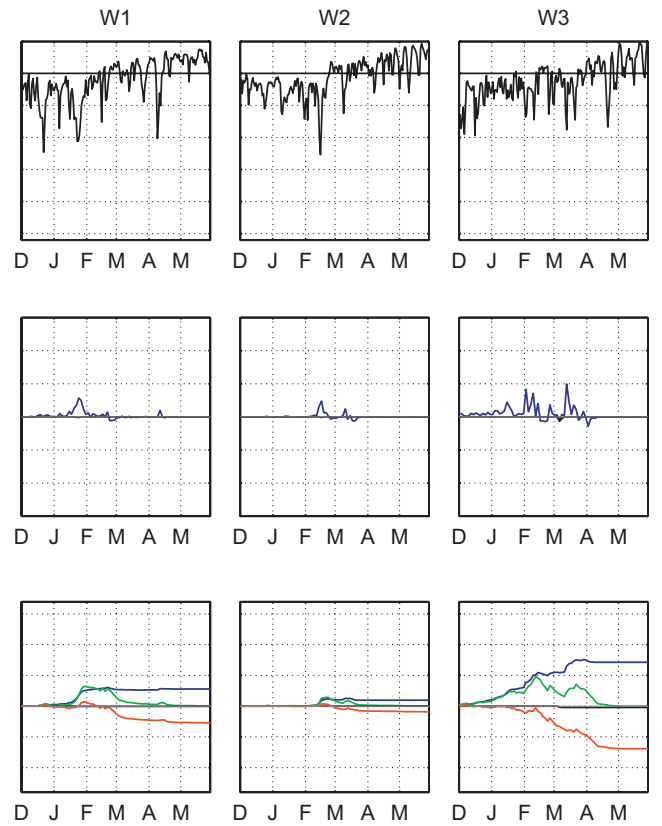

Fig. 4. Evolution of water over the Gulf of Lions shelf during the selected years of the present period. (a) Heat flux, $Q=-H L$, averaged over the NWMS (W $\mathrm{m}^{-2}$ ). (b) DW surface formation (blue) and net transport (black) across the shelf-slope boundary (unit: Sv). DW import is negligible and net transport is actually equal to the export, import and export were therefore not plotted for the sake of clarity. (c) Cumulated volumes of DW formed at the surface (Surf, blue), stored ( $V$, green), transported (Trans, black) and mixed (Mix, red) (unit: $\mathrm{km}^{3}$ ). A positive (resp. negative) value for Surf, Trans and Mix corresponds to production (resp. consumption). (d) Bottom down-slope current (unit: $\mathrm{m} \mathrm{s}^{-1}$ ) and (e) bottom density (unit: $\mathrm{kg} \mathrm{m}^{-3}$ ) at the intersection of the SDS boundary and the Cap Creus canyon.

slower. DW stays therefore longer over the shelf, and this further increases the consumption by mixing.

Surf at the end of the DW formation period is similar for W3 and C3, however, all the DW are consumed by mixing during W3 while a large part of the DW is stored then exported during C3 (Fig. 4c). The surrounding water density difference still explains this difference. Indeed, the heat loss in December is stronger for C3 than for W3 (Fig. 4a), the water density over the shelf is therefore higher at the beginning of January (not shown), when surface formation begins. DW export is therefore not only related to the amount of DW formed, but also to the structure of the water column, which also depends on the atmospheric conditions.

\subsection{Export of $D W$}

Export of DW from the shelf occurs only between mid-January and end of March (Fig. 4b). It does not occur continuously during this period, but shows a strong episodic nature, with flows of DW crossing the shelf-slope boundary, in agreement with observations (Béthoux et al., 2002; Ivanov et al., 2004). As for the DW formation, export of DW is highly correlated with the atmospheric heat loss, with a 0.85 correlation factor between $H L_{D J F M}$ and the total quantity of DW exported during the year, Trans ${ }_{T O T}$.

Previous observations (Béthoux et al., 2002; Canals et al., 2006) and numerical studies (Estournel et al., 2003; Dufau-Julliand et al., 2004; Ulses et al., 2008) showed that due to gravity currents but also to the cyclonic circulation induced by the northwesterly winds, DW formed over the shelf flows southward on the shelf along the coast and escapes the Gulf of Lions shelf at its southwestern (SW) end. There, due to the narrowing of the shelf, a part of this water escapes it by cascading down the canyons, mainly down the CC and the Lacaze-Duthiers canyons (LC). The remaining part continues on the shelf along the Spanish coast. The model reproduces correctly these observations, as seen in Fig. 6 where the bottom density and current during a strong cascading event in CC canyon during year C2 are presented (25th February of year C2, see Fig. 4e where the density at the intersection of the CC canyon and the SDS boundary is shown). We therefore examine the location of DW export: when does DW leave the shelf following the coast, and when does it cascade into the deep ocean? The SDS boundary is divided in four parts (see Fig. 2): the 

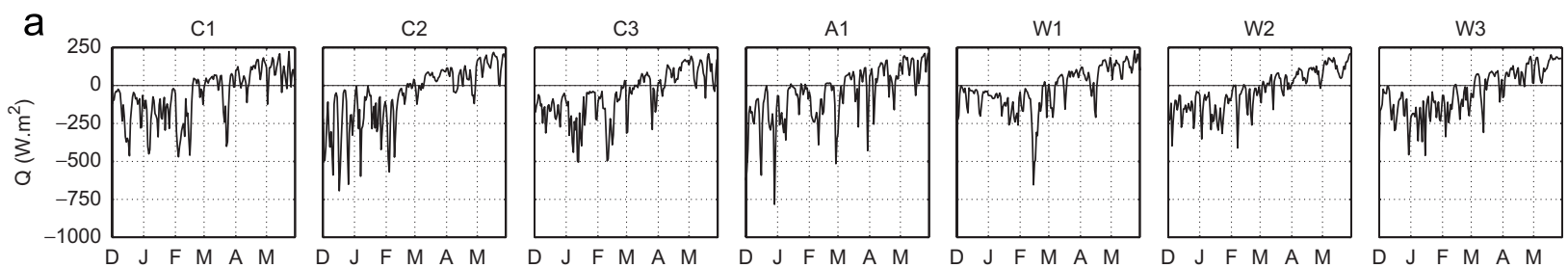

b
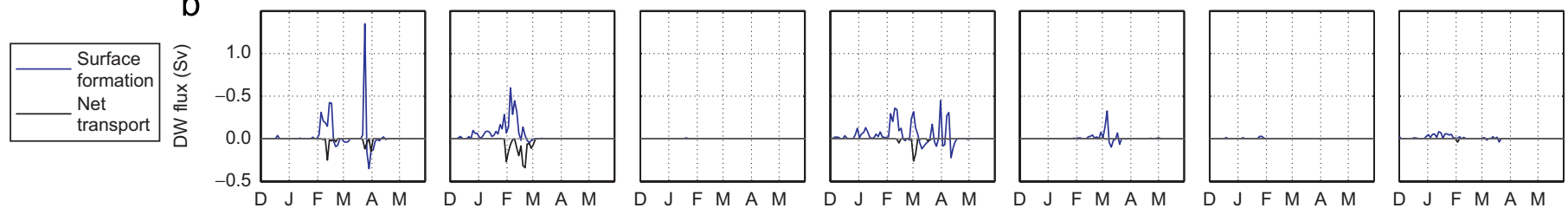

C
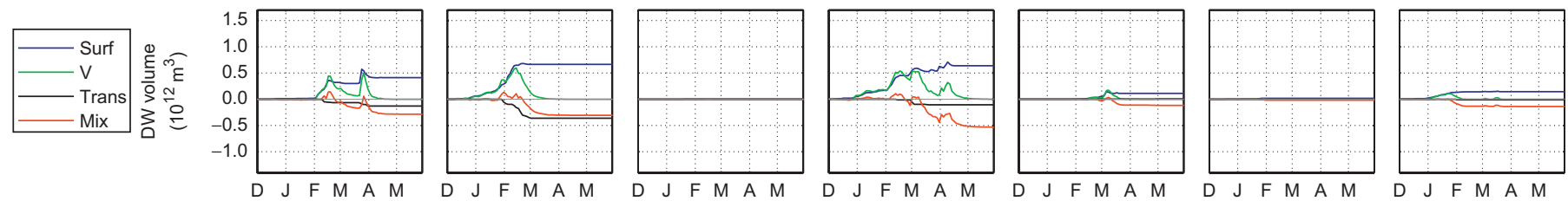

Fig. 5. Evolution of water over the Gulf of Lions shelf during the selected years of the future period. (a), (b), (c): as for Fig. 4 .
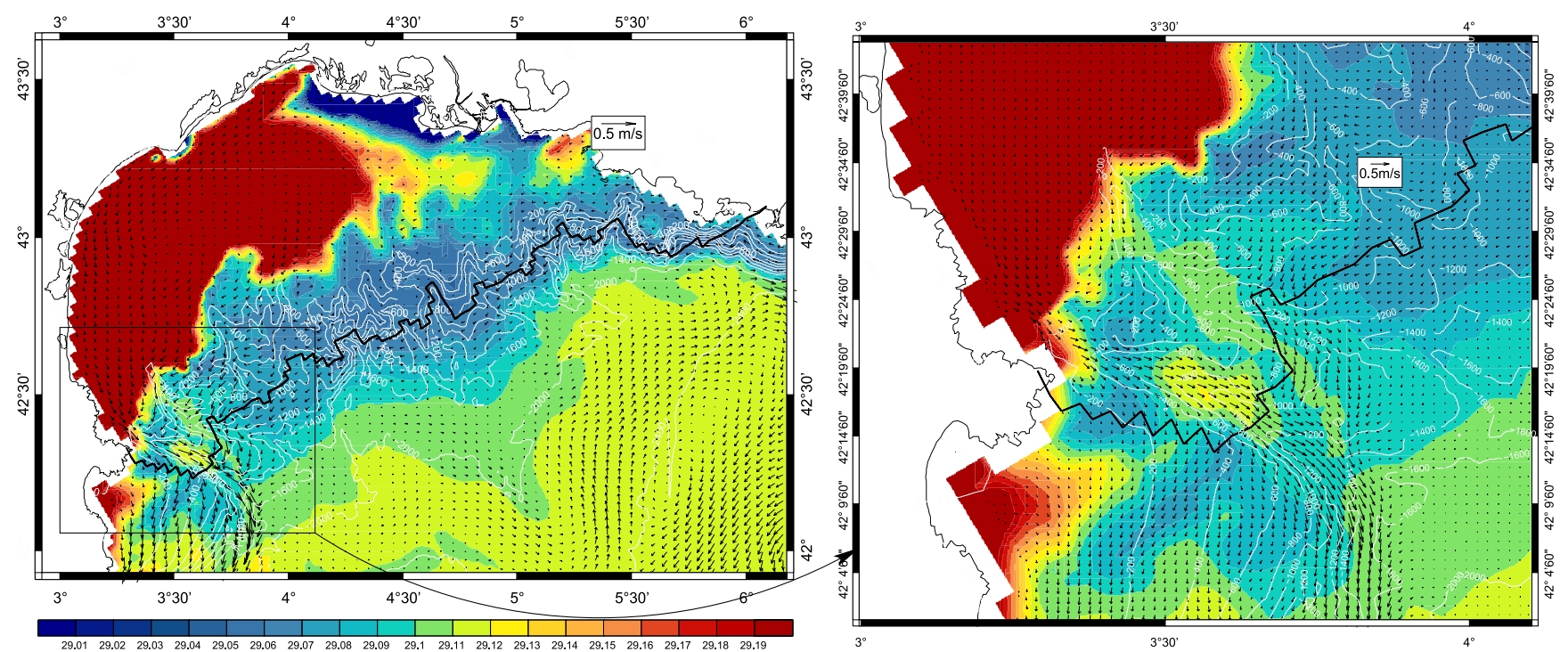

Fig. 6. Cascading event on 25th February of year $\mathrm{C} 2$ of the present period $\left(\rho_{\text {crit }}=29.105 \mathrm{~kg} \mathrm{~m}^{-3}\right)$. Bottom density $\left(\mathrm{kg} \mathrm{m}^{-3}\right.$, map) and current ( $\mathrm{m} \mathrm{s}{ }^{-1}$, arrows). White lines: topography. Black line: SDS boundary.

SW end, the CC canyon, the LC and the remaining part, the northeastern (NE) end. For each year the total quantities of water that escapes the shelf across the whole boundary and across the different parts of the boundary are computed, as well as the mean depth associated to each export. The integrated export as a function of depth is also computed for each year. Results are presented in Fig. 7.

For the average and warm years (A1, W1, W2, W3), the small quantity of DW $\left(<30 \mathrm{~km}^{3}\right)$ crossing the boundary escapes the shelf at the SW end (Fig. 7a) and in the surface layer, above $200 \mathrm{~m}$ depth (Fig. 7b). On the contrary, during cold years (resp. C1, C2, C3), respectively, 390,810 and $270 \mathrm{~km}^{3}$ of DW cross the boundary below $200 \mathrm{~m}$, cascading into the deep ocean (Fig. 7b). This cascading represents, respectively, $53 \%, 59 \%$ and $52 \%$ of the total export, and most of this deep export occurs through the CC canyon (Fig. 7a). In the following, the DW export is defined as the volume of DW flowing across the whole SDS boundary, whereas cascading is defined as the volume of DW flowing across this boundary below $200 \mathrm{~m}$ depth.

Examining the fate of DW formed at the surface for seven years selected over the present period, we show that the quantity of DW formed over, exported from and cascading from the Gulf of Lions shelf shows a strong interannual variability, which is strongly correlated with the atmospheric conditions, namely with the mean heat loss over the NWMS during the December-March period. Export and cascading are negligible during years with weak heat losses, and all the DW formed at the surface are consumed by mixing. On the contrary, during years with strong heat losses, most of the DW formed at the surface is exported (between $60 \%$ and $85 \%$ ). Fifty percent to $60 \%$ of this exported water sinks into the deep ocean, mainly by cascading through the CC canyon. There is a threshold effect in the export and cascading 
a

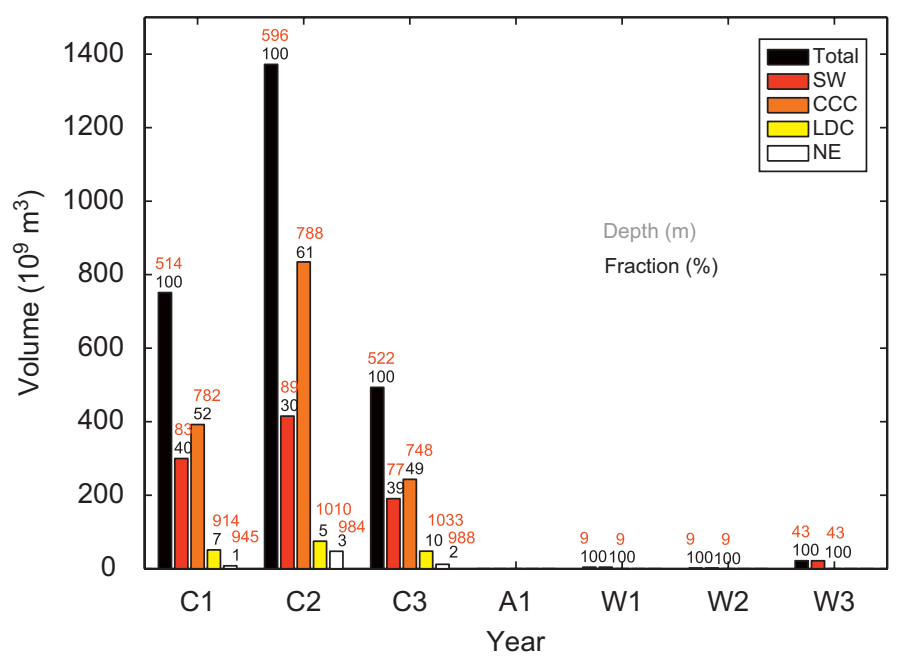

b

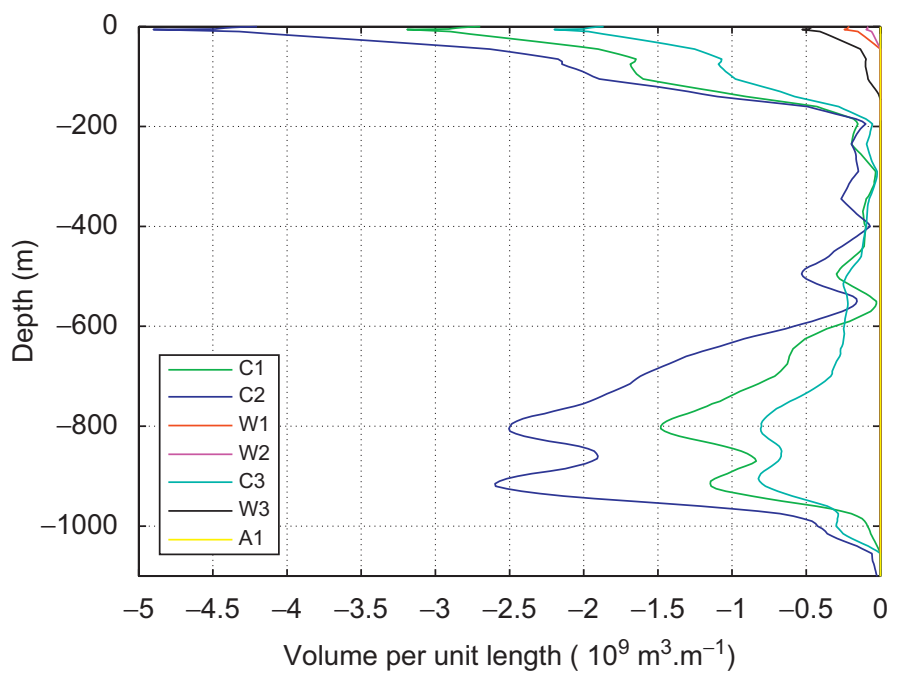

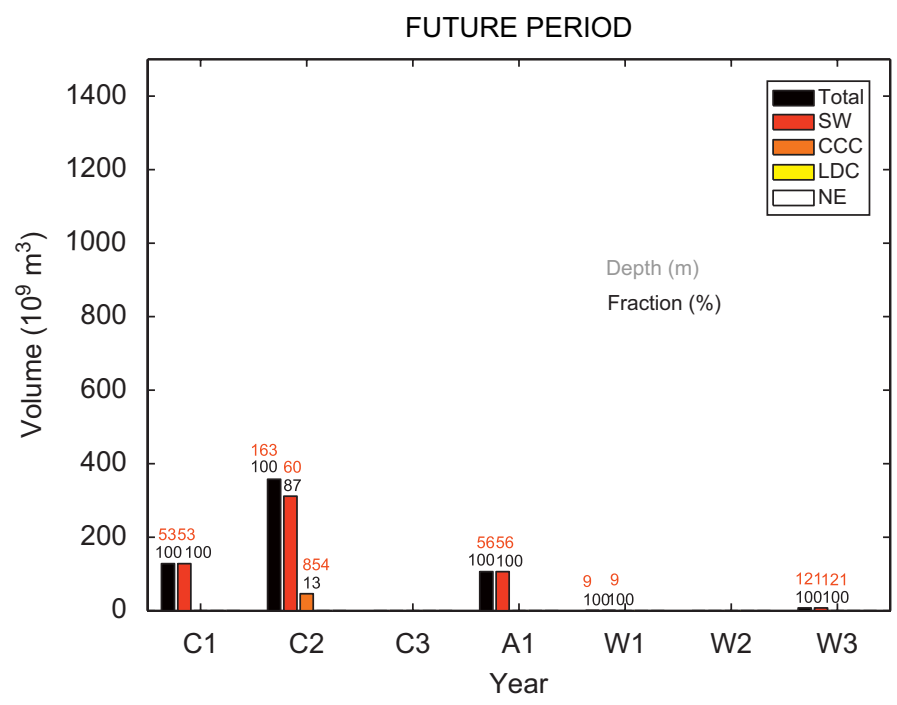

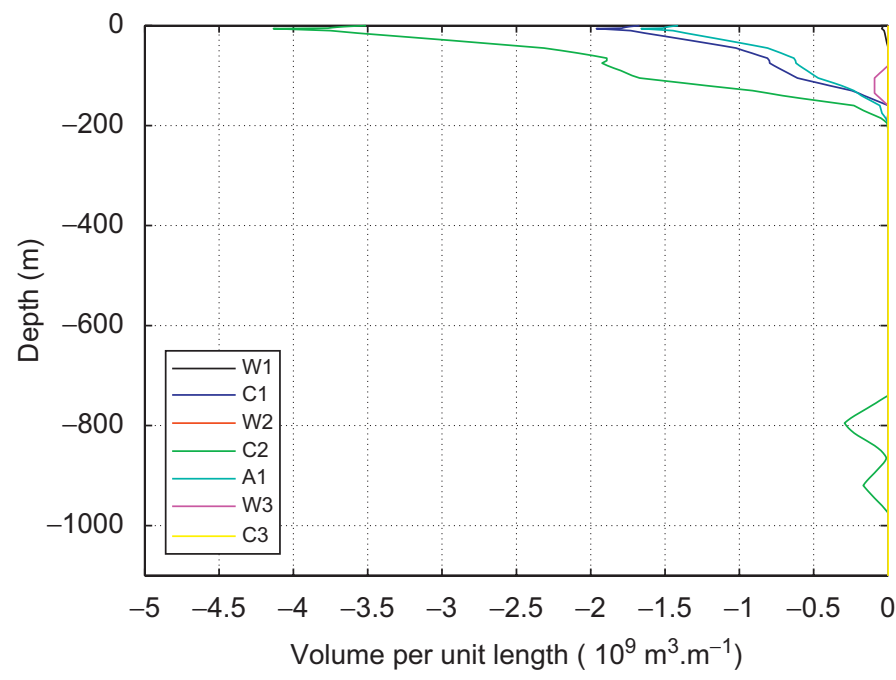

Fig. 7. Export of DW across the SDS boundary during the present and future periods. (a) Export of water through each portion of the SDS boundary (see Fig. 2). For each year, the fraction of water exported through each part of the shelf-slope boundary is indicated in black, and the associated depth is indicated in red. (b) Integrated export as a function of depth.

of DW that do not increase linearly with the DW surface formation but occur only if the winter heat loss is larger than the average value.

\subsection{Comparison with available data}

Béthoux et al. (2002) evaluated that $\sim 440 \mathrm{~km}^{3}$ of DW cascaded down the slope during winter 1998-1999, and Canals et al. (2006) estimated that in 2004-2005 750 $\mathrm{km}^{3}$ of DW sank into the deep ocean by cascading down the CC canyon. Both winters are considered as particularly cold and windy in the NWMS. In our study, for cold years C1, C2 and C3, respectively, 390, 810 and $270 \mathrm{~km}^{3}$ of DW cascades into the deep ocean. These values are of the same order as the observed values. Palanques et al. (2006) observed that DW cascading was more intense in the western part of the shelf, and that sediment fluxes during cascading event down the CC canyon were one to two order of magnitude higher than in the other canyons. Our results are in agreement with those observations: we observe almost no DW export through the NE part of the SDS boundary, and cascading in the CC canyon represents more than $80 \%$ of the deep export during cold years (Fig. 7a).
The density contrast corresponds to the difference between the density of the DW formed over the shelf and the density of the ambient surrounding water. For winter 2004-2005, Canals et al. (2006) observed a $\sim 0.2 \mathrm{~kg} \mathrm{~m}^{-3}$ density contrast. Ivanov et al. (2004) report an average density contrast equal to $0.20 \pm 0.25 \mathrm{~kg} \mathrm{~m}^{-3}$ for the cascades observed in mid-latitudes regions. For the years selected during the present period and with significant DW cascading (C1, C2, C3), we obtain a difference of density of $\sim 0.30 \pm$ $0.02 \mathrm{~kg} \mathrm{~m}^{-3}$ between the DW present over the shelf and the lighter surrounding water, in good agreement with those observations.

Béthoux et al. (2002) observed down-canyon currents up to $60 \mathrm{~cm} \mathrm{~s}^{-1}$ in LC during winter 1998-1999 cascading events. Canals et al. (2006) recorded current speeds up to $80 \mathrm{~cm} \mathrm{~s}^{-1}$ in CC canyon during winter 2004-2005 cascading events. Our model reproduces correctly these current observations: during the modeled cascading events, i.e. when DW bursts occur, we obtain currents varying between 20 and $50 \mathrm{~cm} \mathrm{~s}^{-1}$ in the CC canyon (Fig. 4d).

For the years of the present period, the observed characteristics of DW cascading (geographical characteristics, current speed, density contrast and DW volume) are correctly represented in the numerical simulations. The modeling strategy used in this study appears to simulate correctly DW formation over and export from 
the Gulf of Lions continental shelf under present-day climate conditions. It seems therefore legitimate to apply the same strategy to the future period in order to investigate the possible impact of climate change on this process.

\section{Impact of climate change}

In the present section, the effects of climate change on DW formation over and export from the Gulf of Lions shelf are investigated. For that, the amount of water formed at the surface Surf, stored $V$, formed by transport Trans and formed by mixing Mix are computed for each selected year of the future period as was done in Section 3 for the present period. Results are presented in (Fig. 5). Surface formation occurs during the same season as for the present period, i.e. between end of December and beginning of April (Fig. 5b). The quantity of water formed at the surface and exported from the shelf still shows an important interannual variability, related to the variability of the atmospheric conditions: DW surface formation still occurs during strong heat loss periods (Fig. 5a,b). The temporal behavior of the DW formation is therefore similar to the behavior observed for the selected years of the present period.

The main difference between the present and future periods lies in the volumes of DW formed, exported and cascading. First, the quantity of DW formed at the surface is reduced in average by a factor of 3 between the present and the future periods (Figs. 4c and $5 \mathrm{c}$ ). Moreover, for the years with significant DW formation in the future period $(\mathrm{C} 1, \mathrm{C} 2, \mathrm{~A} 1)$, the percentage of formed water that escapes the shelf $(15-50 \%)$ is smaller than for the three years of significant export during the present period ( $\mathrm{C} 1, \mathrm{C} 2, \mathrm{C} 3,60-85 \%)$ (Figs. $5 \mathrm{c}$ and 7a). The average exported quantity for $\mathrm{C} 1, \mathrm{C} 2, \mathrm{~A} 1$ in the future period is 4.5 times smaller than for $\mathrm{C} 1, \mathrm{C} 2, \mathrm{C} 3$ in the present period. Eventually, there is only one year in the future period with DW export into the deep ocean (C2), and this deep export involves a quantity one order of magnitude smaller than volumes cascading during cold years of the present period (Fig. 7).

As seen in Section 2.1 the heat loss during the winter period, $H L_{D J F}$, averaged over the whole future and present periods is stronger $\left(+15 \mathrm{~W} \mathrm{~m}^{-2}\right)$ for the future period than for the present period. This is also the case for the heat loss during the DW formation period (December-March) for the selected years. This is shown in Fig. 8 where we present the total quantity of DW formed at the surface, Surf TOT, vs. the mean heat loss between December and March, $H L_{D J F M}$. The decrease of volumes of DW formed, exported and cascading can therefore not be attributed to a weakening of the winter heat loss between the 20th century and the end of the 21st century.

In the 140-year simulation performed by Somot et al. (2006), the annual mean buoyancy loss decreases in the NWMS during the $21 \mathrm{st}$ century $\left(-2.9 \times 10^{-9} \mathrm{~m}^{2} \mathrm{~s}^{-3}\right)$, resulting in the decrease of the surface density $\left(-0.45 \mathrm{~kg} \mathrm{~m}^{-3}\right)$. This density decrease is not homogeneous throughout the water column, and is more important at the surface. The vertical density gradient in the Gulf of Lions is consequently larger at the end of the 21st century than during the 20th century. Computing the mean vertical density gradient along the shelf-slope boundary on 20th December, before the DW surface formation, we indeed obtain a $6 \times 10^{-4} \mathrm{~kg} \mathrm{~m}^{-4}$ density gradient averaged over the selected years of the present period vs. a $8 \times 10^{-4} \mathrm{~kg} \mathrm{~m}^{-4}$ average density gradient for the future period. This has two consequences.

First, because of this larger density gradient between the surface and $1000 \mathrm{~m}$ depth, it is more difficult for the surface water to reach the DW criteria (corresponding to the density of the water present in December at $1000 \mathrm{~m}$ along the SDS boundary) in the future period than in the present period, and a larger

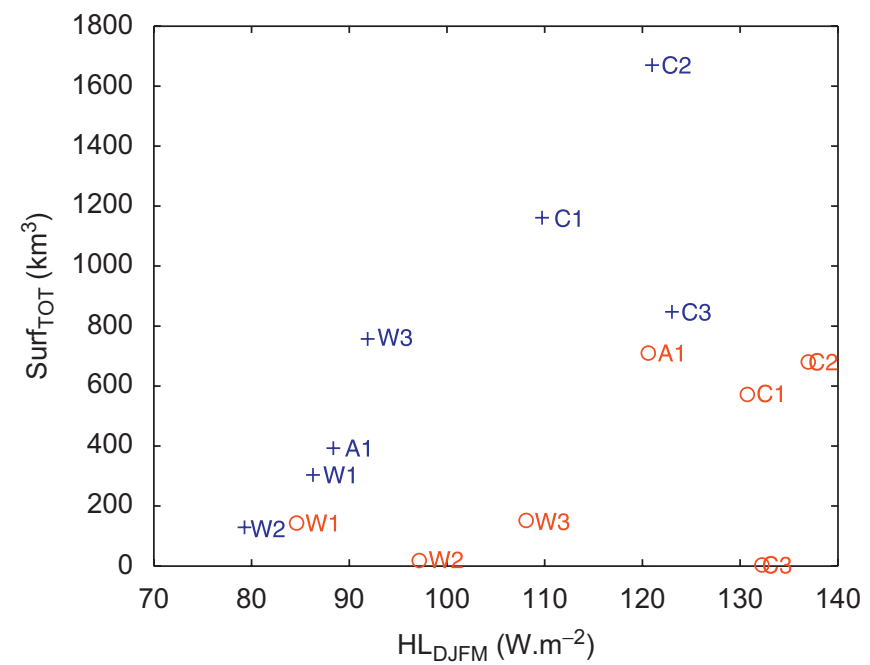

Fig. 8. Dense water formed at the surface $\left(\operatorname{Surf}_{\mathrm{TOT}}, \mathrm{km}^{3}\right)$ vs. heat loss between December and January $\left(H L_{D J F M}, \mathrm{~W} \mathrm{~m}^{-2}\right)$. Blue crosses, respectively, red circles: selected years of the present, respectively, future period.

buoyancy loss is necessary to produce DW at the surface. The total buoyancy loss, $B L$, required to bring the density of the water present over the shelf (corresponding here to the area delimited by the coastline and the SDS boundary, see Fig. 2), before the DW formation (i.e. in December) up to the density criteria $\rho_{\text {crit }}$, is

$B L=\frac{g\left(\rho_{c r i t}-\rho_{G D L, S}\right)}{\rho_{0}} \times D_{G D L}$

where $D_{G D L} \sim 190 \mathrm{~m}$ is the mean depth over this area and $\rho_{G D L S}$ is the density of the water present over this area, considered as being approximately equal to the surface density. For the atmospheric fluxes used for the ORCM and the SYMPHONIE simulations, for the present period, respectively, future period, the heat flux contributes to $87 \%$, respectively, $86 \%$, of the buoyancy flux over the Gulf of Lions shelf between December and March, i.e. during the DW formation period. $B L$ is therefore mainly provided by the heat loss. Using Eq. (3), we compute the total heat loss necessary to increase the shelf water density in December up to the density criteria $H L \sim \rho_{0} C_{p} / g \alpha B L$. Dividing $H L$ by the number of seconds in the DJFM period, we obtain the corresponding average heat loss $H L_{\text {strat }}$, in $\mathrm{W} \mathrm{m}^{-2}$, during the surface formation period. As shown in Section 3, the variability of the density of the water present over the shelf is more than one order of magnitude higher than the variability of the DW criteria among the selected years, and this is also true for the future period (Table 1). We therefore consider the DW criteria as being constant, equal to the average of these criteria for each period (i.e. $\sim 29.1 \mathrm{~kg} \mathrm{~m}^{-3}$, respectively, $\sim 29.0 \mathrm{~kg} \mathrm{~m}^{-3}$, in the present, respectively, future period). The surface density obtained in the NWMS in the ORCM simulation performed by Somot et al. (2006), which provides the boundary conditions for the regional model, is used to compute the average of this heat loss over the 30-year present and future periods, $H L_{\text {strat }, p}$ and $H L_{\text {strat }, f}: H L_{\text {strat }, p}=216.9 \mathrm{~W} \mathrm{~m}^{-2}$ and $H L_{\text {strat }, f}=$ $246.1 \mathrm{~W} \mathrm{~m}^{-2}$. The $29.2 \mathrm{~W} \mathrm{~m}^{-2}$ difference between $H L_{\text {strat } f}$ and $H L_{s t r a t, p}$ corresponds to the additional heat loss required to increase the shelf water density up to the DW criteria in thefuture period compared to the present period, due to the stronger stratification. This additional heat loss explains that the quantity of DW formed in the future is much smaller than in the present, for an equivalent atmospheric heat loss, as observed in Fig. 8. The $15 \mathrm{~W} \mathrm{~m}^{-2}$ average winter heat loss increase between the 20th and 21 st centuries, twice smaller than the additional heat loss, is not sufficient to counterbalance it. As explained in Section 3.2, this 
reduction of the volume of DW formed favors the mixing consumption.

Second, during the DW formation period, DW is surrounded on the shelf with water whose density difference compared with water present at $1000 \mathrm{~m}$ depth before the formation period is larger in the future period than in the present period because of the stronger stratification. The difference between DW and this surrounding water is indeed $\sim 0.35 \pm 0.06 \mathrm{~kg} \mathrm{~m}^{-3}$ in the present vs. $\sim 0.49 \pm 0.11 \mathrm{~kg} \mathrm{~m}^{-3}$ in the future (we do not take into account the two years with practically no surface formation, C3 and W2, in the future period). When DW formed at the surface is mixed with the surrounding water, the resulting water density decreases more in the future period than in the present period.

The stronger vertical density gradient, by reducing the amount of DW formed and the density of the surrounding water, therefore explains that DW is mainly consumed by mixing in the future period, even for the coldest years (Fig. 5c), and that less water is available for export. Furthermore, since the difference between the density of the DW that reaches the SDS boundary and the DW criteria is smaller than for the present period, the DW can less easily cascade into the deep ocean, as observed in Fig. 3: cascading water density is higher than the density of the water present at $2000 \mathrm{~m}$ depth in the present period, whereas it is comparable with the density of water present between 1100 and $1300 \mathrm{~m}$ in the future period. As a result, because of the larger mixing consumption due to the stronger stratification, the fraction of exported water that sinks into the deep ocean is much smaller in the future period than in the present period (Fig. 7): there is only one year (C2) with significant deep export, representing only $8 \%\left(\sim 30 \mathrm{~km}^{3}\right)$ of the total export $\left(\sim 360 \mathrm{~km}^{3}\right), 92 \%$ of the water being exported in the surface layer. In the present period, for the selected years with significant water export, deep export represents between $50 \%$ and $60 \%$ of DW export, with volumes varying between 270 and $810 \mathrm{~km}^{3}$, one order of magnitude higher.

For the selected years of the future period, the change in the water column structure induced by the decrease of annual surface buoyancy loss during the 21 st century explains that, at equivalent winter surface heat loss, less DW is formed at the surface in the future period, a smaller fraction of this DW is exported, and an even smaller fraction sinks into the deep ocean, compared with years of the present period. For these selected years, cascading practically disappears in the future, being reduced at least by $\sim 90 \%$. The results obtained for the selected years of each period are extrapolated to the whole 30 -years periods in the next section.

\section{Extrapolation to the whole present and future periods}

It was shown in Section 3 that DW formation, export and cascading over the Gulf of Lions shelf show a high interannual variability, which is strongly correlated with the atmospheric winter heat loss over the NWMS, $H L_{D J F M}$ (correlation factors $=0.85,0.85$ and 0.83 ). These correlations are used to extrapolate our results to the whole 30-year present and future periods.

Fig. 8 shows that for equivalent atmospheric heat loss, DW surface formation in the future period is much smaller than in the present period. As explained in Section 4, this is due to the stronger stratification of the water column in the Gulf of Lions before the DW formation period. Surface formation is therefore not related only to the atmospheric heat loss, and the initial stratification of the water column must be taken into account. Instead of relating simply the quantity of DW formed at the

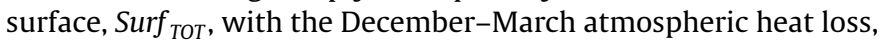
$H L_{D J F M}$, it is more meaningful to relate $\operatorname{Surf}_{T O T}$ with the difference between the atmospheric heat loss and the heat loss necessary to bring the shelf water density up to the density criteria, $H L_{D J F M}-H L_{\text {strat }} . H L_{\text {strat }}$ indeed represents the heat loss necessary to bring the shelf water up to the criteria, and this difference can be considered as the "effective" heat loss $H L_{\text {eff }}$, i.e. the heat loss responsible for DW formation. The values of $H L_{\text {strat }}$ computed in Section $4, H L_{\text {strat, } p}$ and $H L_{\text {strat } f}$, are used in the following analysis. Surf $_{\text {TOT }}$ is plotted vs. $H L_{D J F M}-H L_{\text {strat }}=H L_{\text {eff }}$ in Fig. 9a. The relationship between the DW formed quantity and the "effective" heat loss seems to be the same for the present and future periods. A linear regression analysis of the form $y=a x+b$ between $y=$ Surf $_{\text {TOT }}$ and $x=H L_{\text {eff }}$ is performed. The corresponding fit, resulting in a $13.8 \%$ relative error, is shown in Fig. 9a. The relative error is given by

$\varepsilon=\frac{1}{14} \sum_{\text {SEL }} \frac{\mid \text { Surf }_{\text {TOT,predicted }}-\text { Surf }_{\text {TOT,model }} \mid}{\operatorname{MEL}_{\text {SEL }}\left(\text { Surf }_{\text {TOT,model }}\right)}$

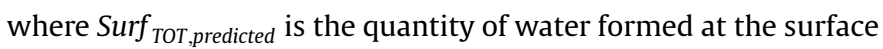
during each year using the linear equation, Surf TOT,model $_{\text {is }}$ the quantity predicted by the model, and SEL is the ensemble of the 14 selected years. The obtained regression is then used to estimate the surface formation volume for each year of the present and future periods: $\operatorname{Surf}_{\text {TOT }}=\operatorname{Max}\left(0, a \times H L_{e f f}+b\right)$ (see Figs. 9a (dots) and 10). Taking the average of this value over the whole period, the mean annual surface formation volume for the present period is $788 \mathrm{~km}^{3}$ with a $421 \mathrm{~km}^{3}$ standard deviation, and $397 \mathrm{~km}^{3}$ with a $312 \mathrm{~km}^{3}$ standard deviation for the future period. For both periods the interannual variability is high, of the same order as the average value. In average, the quantity of DW formed at the surface is divided by 2 between the 20th century and the end of the 21 st century, due to the strengthening of the stratification. For the present period, we obtain one year, out of 29 , with a zerosurface formation, vs. 5 for the future period.

A relation $y=f(x)$ between $x=H L_{e f f}$ and the total net exported quantity of DW, $y=$ Trans $_{T O T}$, is then established. It was observed in Section 3 that Trans $_{T O T}$ was negligible for the warm and average years (for which $H L_{D J F M} \leqslant \overline{H L_{D J F M}, p}$, where the overbar denotes the average over the 30 years), corresponding to a threshold effect of the winter heat loss. Following this observation, we consequently assume empirically that export is possible only if the effective heat loss is larger than the average effective heat loss over the 30 years of the present period: $H L_{\text {eff }} \geqslant \overline{H L}_{e f f, p}$, equivalent to $H L_{D J F M} \geqslant \overline{H L_{D J F M, p}}$ for the present period. This implies that $f(x)$ verifies

$$
\begin{cases}f(x)=0 & \text { for } x<H L_{\text {eff, min }} \\ f(x)=a x+b & \text { for } x \geqslant H L_{\text {eff, min }}\end{cases}
$$

for both periods, where $H L_{\text {eff, min }} \geqslant \overline{H L_{\text {eff, }, p}}$ is the minimum effective heat loss for which export begins. The continuity of $f(x)$ at $x=$ $H L_{\text {eff, min }}$ provides $b=-a \times H L_{\text {eff,min. }}$. We performed a linear regression analysis of the form $y=a x^{\prime}$ between $x^{\prime}=x-H L_{\text {eff, min }}$ and $y=$ Trans $_{\text {TOT }}$, varying $H L_{\text {eff,min }}$ in $\left[\overline{H L_{\text {eff. }}}=-110 \mathrm{Wm}^{-2}\right.$, $\left.-80 \mathrm{~W} \mathrm{~m}^{-2}\right]$ and using only the selected years verifying $H L_{\text {eff }}>$ $\overline{H L_{e f f . p}}$, i.e. years $\mathrm{C} 1, \mathrm{C} 2, \mathrm{C} 3$ of the present period and year $\mathrm{C} 2$ of the future period. The same method is used to obtain a relation between $x=H L_{\text {eff }}$ and $y=\operatorname{Casc}_{\text {TOT }}$.

The corresponding fit, resulting in a $11 \%$, respectively, $8 \%$, relative error for Trans $_{T O T}$, respectively, Casc $_{T O T}$, is shown in Fig. 9b, respectively, Fig. 9c. The minimum relative error is obtained in

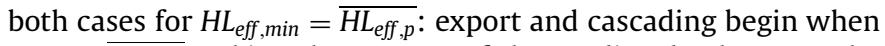
$H L_{e f f}=\overline{H L_{e f f, p}}$. Taking the average of the predicted value over the whole period, the mean annual DW export for the present period is $597 \mathrm{~km}^{3}$ with a $870 \mathrm{~km}^{3}$ standard deviation, and $62 \mathrm{~km}^{3}$ with a $250 \mathrm{~km}^{3}$ standard deviation for the future period. The mean annual DW cascading is $335 \mathrm{~km}^{3}$ with a $489 \mathrm{~km}^{3}$ standard deviation for the present period, and $36 \mathrm{~km}^{3}$ with a $140 \mathrm{~km}^{3}$ 
standard deviation for the future period. Interannual variability is strong for each period. Between the 20th century and the end of the 21st century, DW export and cascading decrease in average by

a

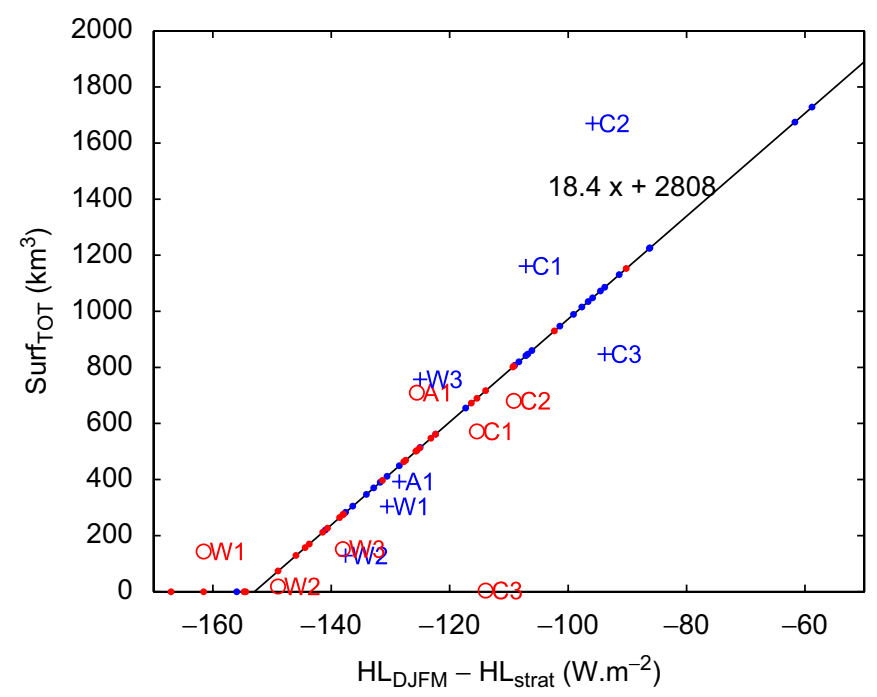

b

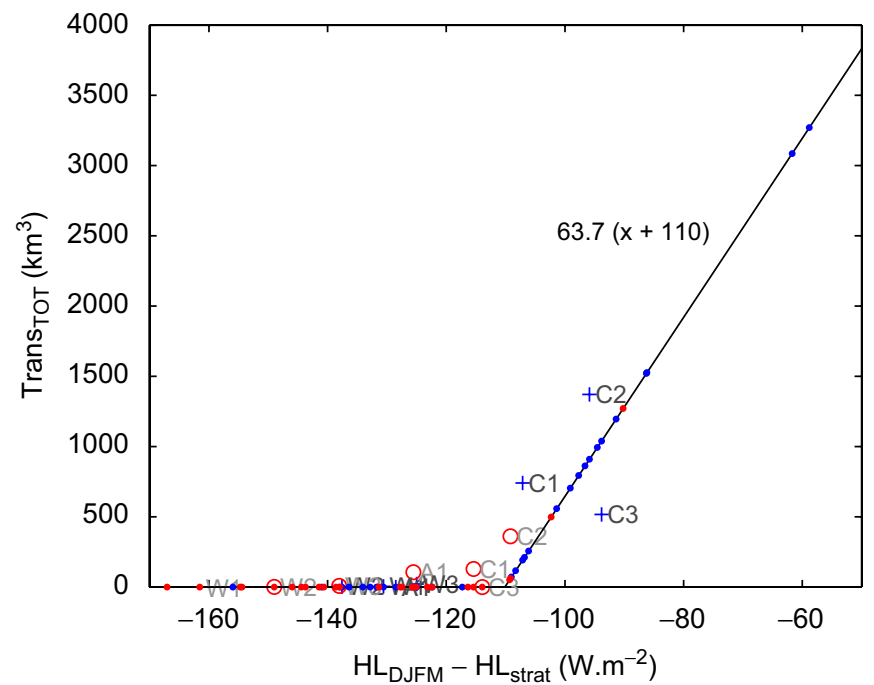

C

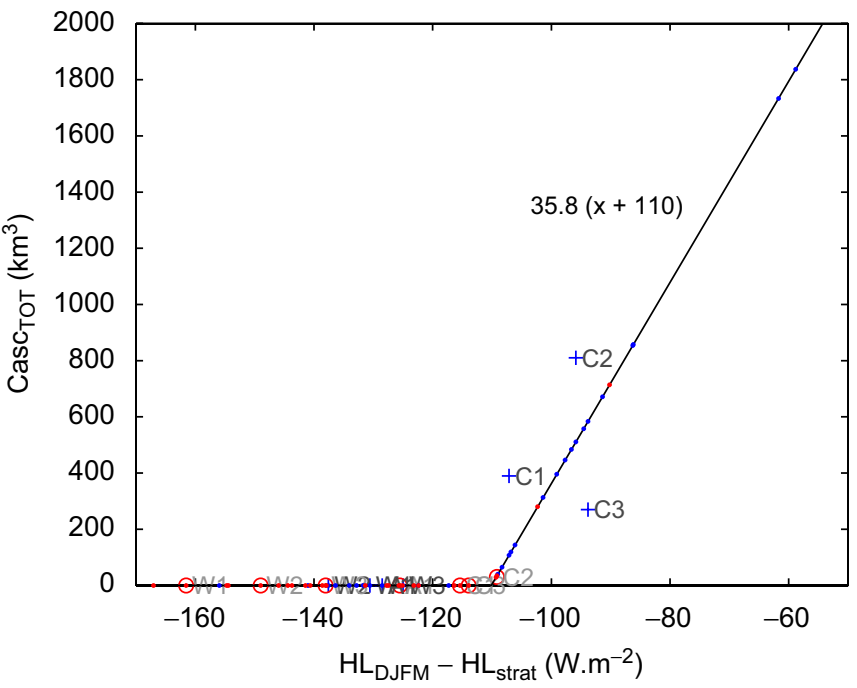

90\%. When considering only years with significant export and cascading, defined as years with exported and cascading volumes larger than $100 \mathrm{~km}^{3}$, one obtains 15 years for the present period, with average export and cascading of 1140 and $640 \mathrm{~km}^{3}$, and 2 for the future period, with average values of 1018 and $570 \mathrm{~km}^{3}$ (Fig. 10). This means that the decrease of the mean annual export and cascading is mainly due to the decrease of the number of years with export and cascading: significant volumes, of the same order as under present climate conditions can still be exported and cascade at the end of the 21 st century, but exceptionally, requiring exceptionally cold winter atmospheric conditions to compensate the stronger stratification.

The $90 \%$ mean decrease is almost twice stronger than the surface formation decrease. As explained in Section 4, in the future period, DW is indeed mainly eliminated by mixing because of the stronger stratification: as a result, $75 \%$ of the water formed at the surface is exported in the present period, vs. $16 \%$ in the future period.

For the years with the strongest heat losses, export can be higher than surface formation (e.g. years 2 and 21 of the present period, Fig. 10): this is due to the fact that the two curves (Surf TOT $_{\text {TO }}$ vs. $H L_{\text {eff }}$ and Trans $s_{T O T}$ vs. $H L_{\text {eff }}$ ) cross each other for high values of the heat loss (Fig. 9). Physically, this corresponds to the fact that the heat loss is so high that the mixing of the DW formed at the surface with lighter surrounding water produces DW, as observed for some of the selected years in Section 3, resulting in a significant increase of the quantity of DW present over the shelf and then exported.

\section{Uncertainties}

In the previous sections, numerical simulations performed with the regional oceanic model SYMPHONIE, forced at its lateral boundary by the ORCM OPA and at the surface by the ARCM ARPEGE-Climate under the IPCC A2 scenario forcings, were used to investigate the impact of interannual atmospheric variability and climate change on the quantities of DW formed over, exported from and cascading from the Gulf of Lions shelf. Respectively, 50\%, 90\% and 90\% decreases between the 20th century and the end of the 21st century were estimated for the average yearly volume of DW formed, exported and cascading. In this section, we provide an estimate of the uncertainties associated to the choice of the DW criteria, the parameters of the regional oceanic model, the water flux, the choice of the atmospheric model and the choice of the IPCC scenario.

\subsection{Sensitivity test to the DW criteria}

In Section 2.3 the DW density criteria were defined as $\rho_{\text {crit }}=\rho_{\text {bottom }}+\Delta \rho$, where $\rho_{\text {bottom }}$ is the mean density at the bottom of the boundary during the month preceding cascading, i.e. December, and $\Delta \rho=0.03 \mathrm{~kg} \mathrm{~m}^{-3}$ is a constant density anomaly. Sensitivity tests to these criteria are performed here by varying $\Delta \rho$. Fig. 3 shows that the DW patch could also be defined using $\Delta \rho=0.02 \mathrm{~kg} \mathrm{~m}^{-3}$ instead of $\Delta \rho=0.03 \mathrm{~kg} \mathrm{~m}^{-3}$, we therefore vary $\Delta \rho$ between 0.02 and $0.04 \mathrm{~kg} \mathrm{~m}^{-3}$.

Fig. 9. DW formed, exported and cascading for the present (blue) and future (red) periods. (a) Total DW volume formed at the surface during a given year, Surf TOT $_{\text {, }}$ as a function of the difference between the mean heat loss during the formation period for this given year and the mean heat loss corresponding to the stratification, $H L_{D J F M}-H L_{\text {strat }}$. (b) and (c) Same for exported water TransToT and cascading water Casc $_{T O T}$. + and $\circ$ : selected years for the present and future periods. $\bullet$ : results obtained for each year of the present and future period using the obtained regression. Black line: linear regression analysis. 

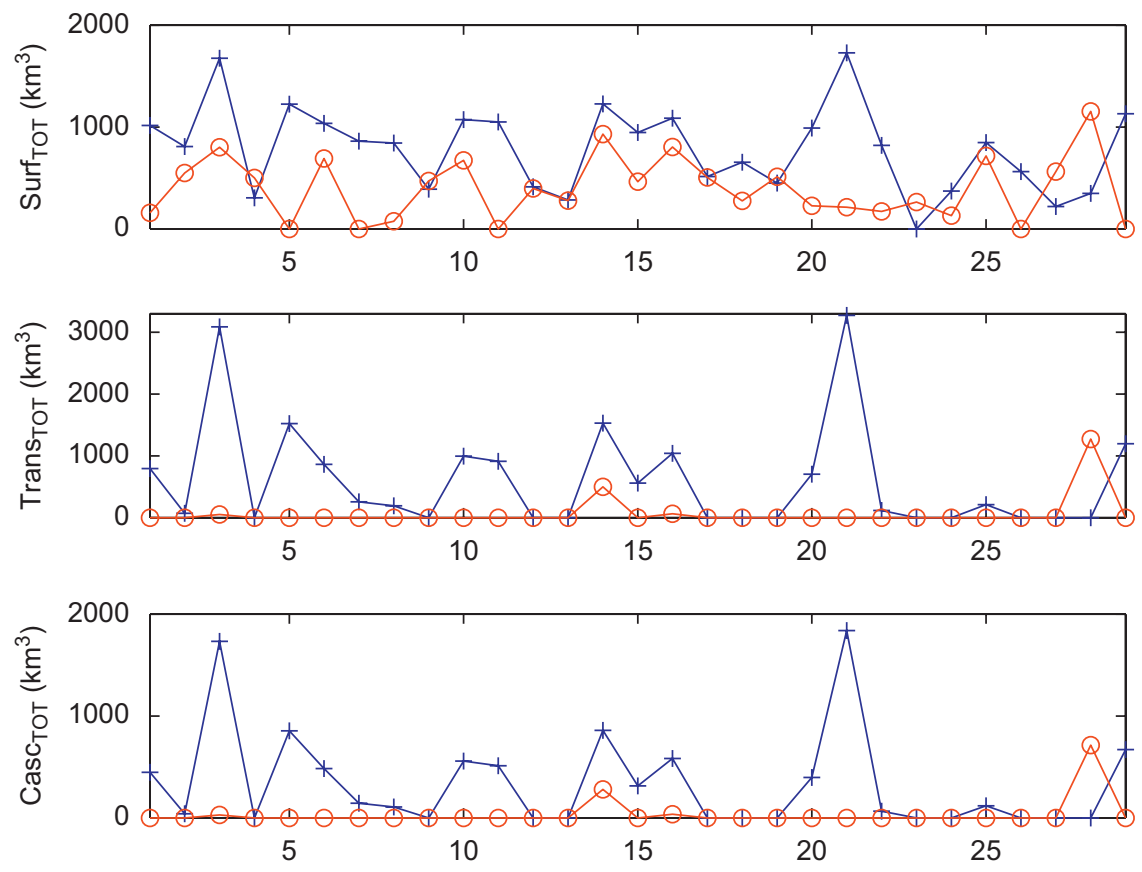

Fig. 10. DW formed, exported and cascading for each year of the present (blue, $\circ$ ) and future (red, + ) periods.

Table 2

Mean and standard deviation (bracket) over the selected years of the present period of the relative difference between the total volume of DW formed at the surface (Surf), exported (Trans), and cascading (Casc) obtained for different values of $\Delta \rho$ and the volume obtained for $\Delta \rho=0.03 \mathrm{~kg} \mathrm{~m}^{-3}$, |value vear,$\Delta \rho_{-}$ value $_{\text {year }, 0.03} \mathrm{l} /$ value $_{\text {year }, 0.03}$

\begin{tabular}{lllll}
\hline$\Delta \rho$ & 0.02 & 0.025 & 0.035 & 0.04 \\
\hline Surf & $0.18(0.19)$ & $0.10(0.12)$ & $0.11(0.09)$ & $0.17(0.09)$ \\
Trans & $0.44(0.44)$ & $0.29(0.35)$ & $0.12(0.12)$ & $0.25(0.17)$ \\
Casc & $1.32(0.63)$ & $0.53(0.30)$ & $0.28(0.07)$ & $0.47(0.08)$
\end{tabular}

Values for cascading are computed using results for years with significant cascading, i.e. $\mathrm{C} 1, \mathrm{C} 2, \mathrm{C} 3$.

The impact of the density criteria choice on the absolute quantities is first examined for the present period. The mean and standard deviation over the selected years of the present period of the relative difference between volumes obtained using $\Delta \rho \in$ $[0.02,0.025,0.035,0.040] \mathrm{kg} \mathrm{m}^{-3}$ and volumes obtained using $\Delta \rho=0.03 \mathrm{~kg} \mathrm{~m}^{-3}$, (|value year,$\Delta \rho-$ value $_{\text {year }, 0.03} \mid$ value $_{\text {year }, 0.03}$, are given in Table 2 . The impact of $\Delta \rho$ on the amount of DW formed at the surface is much weaker than the impact on the volumes of exported and cascading DW, which vary by a factor of 2 . The density of the DW formed at the surface is indeed much larger than the criteria (see for example Fig. 6), explaining that the impact of the criteria on the quantity of DW formed is relatively weak. On the contrary, since the originally very DW formed at the surface was mixed with lighter water during its way to the boundary, the density of the exported and cascading water is closer to the criteria. The volume of exported and cascading DW therefore depends a lot on the choice of the criteria. Note, however, that values of $\Delta \rho \geqslant 0.03 \mathrm{~kg} \mathrm{~m}^{-3}$ give more realistic values for the cascading volumes than values of $\Delta \rho<0.03 \mathrm{~kg} \mathrm{~m}^{-3}$, which give results that are in the highest range of the observations (see Section 3.4).

Since the objectives of the present study are to investigate first the impact of atmospheric interannual variability on DW formation, export and cascading under present climate conditions, and second the impact of climate change, we are particularly
Table 3

Mean and standard deviation (bracket) over the selected years of the present period of the relative difference between the total volume of DW formed at the surface (Surf), exported (Trans), and cascading (Casc) obtained during years of the present period and year $\mathrm{C} 2$, $\mid$ value $_{\text {year }, \Delta \rho}-$ value $_{\mathrm{C} 2, \Delta \rho} \mid /$ value $_{\mathrm{C} 2, \Delta \rho}$, for different values of $\Delta \rho$

\begin{tabular}{lllllll}
\hline Year & C1 & C3 & A1 & W1 & W2 & W3 \\
\hline Surf & $0.50(0.05)$ & $0.45(0.04)$ & $0.21(0.02)$ & $0.16(0.02)$ & $0.06(0.01)$ & $0.40(0.03)$ \\
Trans & $0.57(0.05)$ & $0.44(0.05)$ & $0(0)$ & $0(0)$ & $0(0)$ & $0.02(0)$ \\
Casc & $0.51(0.03)$ & $0.44(0.08)$ & $0(0)$ & $0(0)$ & $0(0)$ & $0(0)$ \\
\hline
\end{tabular}

interested in the relative values between the years and the periods. We compute for each value of $\Delta \rho$ the difference between volumes obtained for each selected year of each period and for the year with the highest volumes, which is always year $\mathrm{C} 2$ of the present period, |value year,$\Delta \rho-$ value $_{\mathrm{C} 2, \Delta \rho} \mid /$ value $_{\mathrm{C} 2, \Delta \rho}$. Results are presented in Table 3 for the present period and in Table 4 for the future period. For the formation, the export and the cascading and for each year of the future and present periods, the much smaller values of the standard deviation compared to the average value of the relative difference show that the choice of the DW criteria does not have a significant impact on the relative difference between the years and the periods. Our conclusions concerning the relative impacts of atmospheric interannual variability and climate change on DW formation, export and cascading on the Gulf of Lions shelf are independent on the DW criteria.

\subsection{Sensitivity to the parameters of the regional oceanic model}

The parameters used in the high-resolution model can induce uncertainty in the results. The fate of the DW formed over the shelf could be particulary dependant on the horizontal diffusivity and on the bottom friction. Given the wide range of variability obtained, an error on a large amount of water formed or transported will have a much larger impact on the variability of 
Table 4

Mean and standard deviation (bracket) over the selected years of the future period of the relative difference between the total volume of DW formed at the surface (Surf), exported (Trans), and cascading (Casc) obtained during years of the future period and year C2 of the present period, $\left|v a l u e_{y e a r, \Delta \rho}-v_{a l u e}{ }_{C 2, \Delta \rho}\right| / v a l u e_{C 2, \Delta \rho}$, for different values of $\Delta \rho$

\begin{tabular}{lllllll}
\hline Year & C1 & C2 & C3 & A1 & W1 & W3 \\
\hline Surf & $0.25(0.02)$ & $0.36(0.07)$ & $0(0)$ & $0.40(0.02)$ & $0.07(0.02)$ & $0.01(0)$ \\
Trans & $0.10(0.04)$ & $0.28(0.07)$ & $0(0)$ & $0.08(0.03)$ & $0(0)$ & $0.08(0.01)$ \\
Casc & $0(0)$ & $0.03(0.01)$ & $0(0)$ & $0(0)$ & $0(0)$ & $0(0)$ \\
\hline
\end{tabular}

the averaged results for each period than an error on a small amount of water. Therefore, we tested the sensitivity to the different parameters by performing additional simulations for the most productive year of the present period, year $\mathrm{C} 2$.

\subsubsection{The horizontal diffusivity}

In SYMPHONIE, a classic centered advection scheme is used for the velocity (Arakawa and Suarez, 1983), with the horizontal viscosity $K_{H}=60 \mathrm{~m}^{2} \mathrm{~s}$. There is no explicit horizontal viscosity for the tracers, since it is implicity included in the numerical advection scheme, a hybrid centered/upstream scheme adapted from Beckers (1995). We performed sensitivity tests to the horizontal diffusivity for the velocity $K_{H}$ multiplying and dividing it by 2 in the simulation for year $\mathrm{C} 2$ of the present period. The maximum variation is $\Delta \sim 7 \%$ for the annual volume of DW formed at the surface. The annual export ( $\Delta \sim 16 \%)$ and cascading $(\Delta \sim 25 \%)$ are more sensitive to the horizontal diffusivity. This seems physically logical: the velocity influences the fate of DW when this DW is moving, therefore not when it is formed at the surface, but rather when it is exported.

\subsubsection{The bottom friction}

The bottom friction should only play a role when the DW flows along the bottom. It should consequently not influence considerably the surface formation, but rather the export and the cascading. It is indeed one of the key factors in the cascading process, as explained by Simpson (1987): large scale geostrophic currents tend to flow along the bathymetric isolines, inhibiting the exchanges between the shelf and the open ocean through the continental slope. The bottom friction and the channeling by the topography counteract this geostrophic tendency, allowing the DW formed over the shelf to flow down the slope by gravity current. In SYMPHONIE, the bottom friction $\overrightarrow{\tau_{b}}$ is related to the bottom velocity $\overrightarrow{V_{b}}$ (equal in the model to the velocity at the first level above the bottom) by a quadratic relationship:

$\overrightarrow{\tau_{b}}=\rho_{0} C_{D}\left\|\overrightarrow{V_{b}}\right\| \overrightarrow{V_{b}}$

where $C_{D}$ is the bottom friction coefficient, related to the bottom roughness $z_{0}$ by a logarithmic low:

$C_{D}=\left(\frac{\kappa}{\log \left(\frac{z_{1}}{z_{0}}\right)}\right)^{2}$

with $\kappa=0.41$ the Von Karman constant and $z_{1}$ the height of the first level above the bottom. In our model, $z_{0}=1 \mathrm{~cm}$, following Blumberg and Mellor (1987). This is an upper bound for the bottom roughness. $5 \times 10^{-4} \mathrm{~m}$ can be considered as a lower bound. This range of values is indeed classically used in sediment transport modeling to take into account the roughness induced by sand, by waves and by bedforms present on the bottom of the sea. We performed a simulation for the year $\mathrm{C} 2$ of the present period, with $z_{0}=5 \times 10^{-4} \mathrm{~m}$. As expected, the sensitivity of the quantity of water formed at the surface to the bottom friction parame- trization is small (the annual surface formation decreases by $-4 \%$ ), but the sensitivity of the export, that decreases by $27 \%$ and of the cascading, that decrease of 55\%, are more important.

Finally, the annual quantity of DW formed at the surface is not very sensitive to the parameters of the model, and one can estimate the computation error for this volume to be less than $10 \%$. The export and cascading are more sensitive to those parameters, in particular to the bottom friction. An upper bound for the computation error can be estimated from the sensitivity tests made here as $\sim 30 \%$ for the export and $\sim 55 \%$ for the cascading. The influence of those parameters on the absolute results obtained for each given year is therefore not negligible. However, an error on a given parameter would change the results in the same direction (increase or decrease) for each year. As for the uncertainty due to the DW criteria, the results concerning the relative differences between different years of the same period or between the present and the future period should therefore not be fundamentally different.

\subsection{Sensitivity to the water flux}

Due to the weaker ability of ARCM to simulate the precipitations, the surface atmospheric water loss term represents a source of uncertainty in our study ( $\mathrm{Li}$ et al., 2006). However, the boundary conditions for SYMPHONIE are prescribed using the results of the simulation of Somot et al. (2006), who observed that the $(E-P)$ term simulated by their ARCM is in good agreement with the observations. In winter, over the shelf, the atmospheric water flux contribution to the buoyancy flux is one order of magnitude smaller than the heat flux contribution, as seen in Section 4. For a given winter, an error on the winter atmospheric water flux term should therefore not influence significantly the stratification and the results.

The value of the coefficients used to compute the future period Rhône runoff is another source of uncertainty. For the 10 different ARCMs of the PRUDENCE project (see Section 6.4), the decrease of the Rhône runoff (see Section 2.2) between the 20th and the 21st centuries varies between $0 \%$ and 20\% (Hagemann, personnal communication), $20 \%$ being the value obtained in the ARPEGEClimate simulation (Gibelin and Déqué, 2003) and used here. Considering only the effect of the Rhône river variation, the present studies therefore provides a lower bound for the induced decrease of DW formation, export and cascading. A weaker runoff decrease will indeed contributes more to the enhancement of the stratification.

The runoff variation between the present and the future periods induces an average buoyancy variation over the shelf that is one order of magnitude smaller than the winter atmospheric buoyancy flux. However, contrary to the atmospheric buoyancy flux, the Rhone buoyancy flux is concentrated in one point of the domain, and can locally influence the water column structure. It is therefore more difficult to estimate the effect of a small variation of this source of buoyancy. Performing a simulation for the most productive year of the future period (C2) with no runoff variation 
compared to the present period, the DW surface formation, export and cascading are, respectively, $10 \%, 40 \%$, and $100 \%$ smaller than in the simulation with the $20 \%$ runoff decrease. For a given winter in the future period, the impact of the Rhone runoff of the surface formation is small. The impact on the export and cascading seems more spectacular, one should, however, keep in mind that this impact concerns values that are already very small. Extrapolating those results to the whole period, one can estimate that the uncertainty on the Rhône runoff would cause the DW surface formation, export and cascading decrease between the 20th and 21 st centuries to vary, respectively, between $50 \%$ and 55\%, $90 \%$ and $94 \%$ and $90 \%$ and $100 \%$.

On the short term, errors on the winter water flux term and on the runoff coefficient would not change significantly the results concerning the impact of climate change.

However, on the annual scale, the atmospheric water flux and heat flux contributions are similar ( $\sim 50 \%$ for the present period). The annual buoyancy gain due to the Rhone runoff is almost twice the average annual atmospheric buoyancy loss. An error on the annual atmospheric water flux or on the river runoff variation could therefore influence significantly the annual buoyancy flux that plays a major role in the evolution of the water column stratification during the 21 st century. This would have an impact on the results regarding the formation and fate of DW for the future period. To investigate the sensitivity of our results to longterm variations of the river and atmospheric water fluxes, it would now be necessary to perform other 140-year ORCM simulations.

The impact of the interannual variability of the Rhone river runoff was not investigated in this paper. The winter runoff can vary by a factor of 2 from one year to another. Such a variation represents a variation of buoyancy flux of the same order as the winter atmospheric buoyancy loss. One can then expect the interannual variability of the Rhone river runoff to influence the water column stratification and the DW shelf formation and fate, on the short term as well as on the long term. Further modeling studies should be performed to investigate this effect.

\subsection{Sensitivity test to the ARCM}

In the present study, the results of a simulation performed with the ARCM ARPEGE-Climate (Gibelin and Déqué, 2003), used by Somot et al. (2006) to force the ORCM OPA, were used to force the regional model SYMPHONIE at the surface. However, several other atmospheric models are available, for example 10 ARCMs were used to simulate the present-day climate over Europe, as well as the impact of climate change by the end of the $21 \mathrm{st}$ century, in the framework of the PRUDENCE project (Christensen et al., 2002). Each ARCM is forced at its boundaries by an AOGCM. Analyzing the results of these simulations for the present period (1961-1990), Jacob et al. (2007) showed that the main ARCM systematic biases vary among the models, in particular the bias of the winter air temperature over the land. Winter heat loss can therefore be expected to show a non-negligible bias across the different models. Déqué et al. (2007) assessed uncertainties in projected climate change, examining uncertainties due to the $\mathrm{ARCM}$, to the forcing AOGCM, and to the natural internal variability due to the chaotic nature of the atmosphere behavior. The objectives of the present section are to assess uncertainties in DW formation and export modeling in the Gulf of Lions shelf due to the choice of the ARCM, the choice of the AOGCM, the natural variability and the choice of the climate change scenario.

For this purpose, climate simulations performed with the eight ARCMs for which data necessary to compute the winter heat loss are available were selected for the present (1961-1990, 14 simulations) and future (2071-2100, 21 simulations) periods
Table 5

List of 1961- 1990 simulations used in this study

\begin{tabular}{lllll}
\hline Institute & Run name & ARCM & AOGCM & Res. (km) \\
\hline CNRM $\left({ }^{*}\right)$ & DA9 & ARPEGE & ARPEGE & 50 \\
UCM $\left(^{*}\right)$ & control & PROMES & HadAM3H & 50 \\
DMI $\left.{ }^{*}\right)$ & HC1 & HIRHAM & HadAM3H & 50 \\
DMI & HC2 & HIRHAM & HadAM3H & 50 \\
DMI & HC3 & HIRHAM & HadAM3H & 50 \\
DMI & F25 & HIRHAMh & HadAM3H & 25 \\
DMI & ecctrl & HIRHAM & ECHAM4 & 50 \\
ETH $\left({ }^{*}\right)$ & HCCTL & CHRM & HadAM3H & 55 \\
GKSS $\left({ }^{*}\right)$ & CTL & CLM & HadAM3H & 55 \\
HC $\left({ }^{*}\right)$ & adeha & HadRM3P & HadAM3H & 50 \\
MPI $\left({ }^{*}\right)$ & 3003 & REMO & HadAM3H & 55 \\
SMHI $\left({ }^{*}\right)$ & HCCTL & RCAO & HadAM3H & 50 \\
SMHI & MPICTL & RCAO & ECHAM4 & 50 \\
SMHI & HCCTL22 & RCAOh & HadAM3H & 22
\end{tabular}

The eight simulations marked with $\left({ }^{*}\right)$ were used to build the 240-year ensemble mean ENS. ARCM, Regional Climate Model; AOGCM, Atmosphere Ocean Global Climate Model, Res., spatial resolution.

Table 6

List of 2071-2100 simulations used in this study

\begin{tabular}{llllll}
\hline Institute & Run name & ARCM & AOGCM & Res. $(\mathrm{km})$ & Sc. \\
\hline CNRM & DE9 & ARPEGE & ARPEGE & 50 & A2 \\
CNRM & DC9 & ARPEGE & ARPEGE & 50 & B2 \\
CNRM $\left(^{*}\right)$ & DE6 & ARPEGE & HadAM3H & 50 & A2 \\
CNRM & DE5 & ARPEGE & HadAM3H & 50 & B2 \\
UCM $\left(^{*}\right)$ & a2 & PROMES & HadAM3H & 50 & A2 \\
UCM & b2 & PROMES & HadAM3H & 50 & B2 \\
DMI $\left(^{*}\right)$ & HS1 & HIRHAM & HadAM3H & 50 & A2 \\
DMI & HS2 & HIRHAM & HadAM3H & 50 & A2 \\
DMI & HB1 & HIRHAM & HadAM3H & 50 & B2 \\
DMI & S25 & HIRHAMh & HadAM3H & 25 & A2 \\
DMI & ecscA2 & HIRHAM & ECHAM4 & 50 & A2 \\
DMI & ecscA2 & HIRHAM & ECHAM4 & 50 & B2 \\
ETH $\left(^{*}\right)$ & HC-A2 & CHRM & HadAM3H & 55 & A2 \\
GKSS $\left({ }^{*}\right)$ & SA2 & CLM & HadAM3H & 55 & A2 \\
HC $\left({ }^{*}\right)$ & adhfa & HadRM3P & HadAM3H & 50 & A2 \\
MPI $\left({ }^{*}\right)$ & 3005 & REMO & HadAM3H & 55 & A2 \\
SMHI $\left.{ }^{*}\right)$ & HCA2 & RCAO & HadAM3H & 50 & A2 \\
SMHI & HCB2 & RCAO & HadAM3H & 50 & B2 \\
SMHI & MPIA2 & RCAO & ECHAM4 & 50 & A2 \\
SMHI & MPIB2 & RCAO & ECHAM4 & 50 & B2 \\
SMHI & HCA222 & RCAOh & HadAM3H & 22 & A2 \\
\hline
\end{tabular}

The eight simulations marked with $\left({ }^{*}\right)$ were used to build the 240 -year ensemble mean ENS. ARCM, Regional Climate Model; AOGCM, Atmosphere Ocean Global Climate Model, Res., spatial resolution; Sc., IPCC scenario.

(see Tables 5 and 6 ). Each of the eight institutes provides a basis simulation for the present and future periods (denoted by * in Tables 5 and 6), and some institutes provide some additional simulations. The DA9 and DE9 simulations are actually the present and future parts of ARCM simulation used to force the ORCM (see Section 2.1).

The total heat loss $H L$ is the sum of the net longwave flux radiation $L W$, the net shortwave radiation $S W$, the latent heat flux $L H$ and the sensible heat flux SH. Monthly data for $L W$ and $S W$ are directly available on the PRUDENCE project website (prudence.dmi.dk). $L H$ is computed using the monthly evaporation $E$ : $L H=$ $\rho_{0} A E$ where $A=2.47 \times 10^{6} \mathrm{~J} \mathrm{~kg}^{-1}$ is the latent heat of condensation and $\rho_{0}=1020 \mathrm{~kg} \mathrm{~m}^{-3}$ is the reference sea water density. Daily wind velocity and air temperature data were extracted to compute the sensible heat flux: $S H=\rho_{a} C_{p a} C_{h} V_{a}\left(S S T-T_{a}\right)$ where $\rho_{a}=$ $1.2 \mathrm{~kg} \mathrm{~m}^{-3}$ is the air density, $C_{p a}=1004 \mathrm{~J} \mathrm{~kg}^{-1} \mathrm{~K}^{-1}$ is the specific heat of air, $C_{h}=1.2 \times 10^{-3}$ is the Stanton number, $V_{a}$ is the 10 metre wind velocity, SST is the sea surface temperature and $T_{a}$ is 

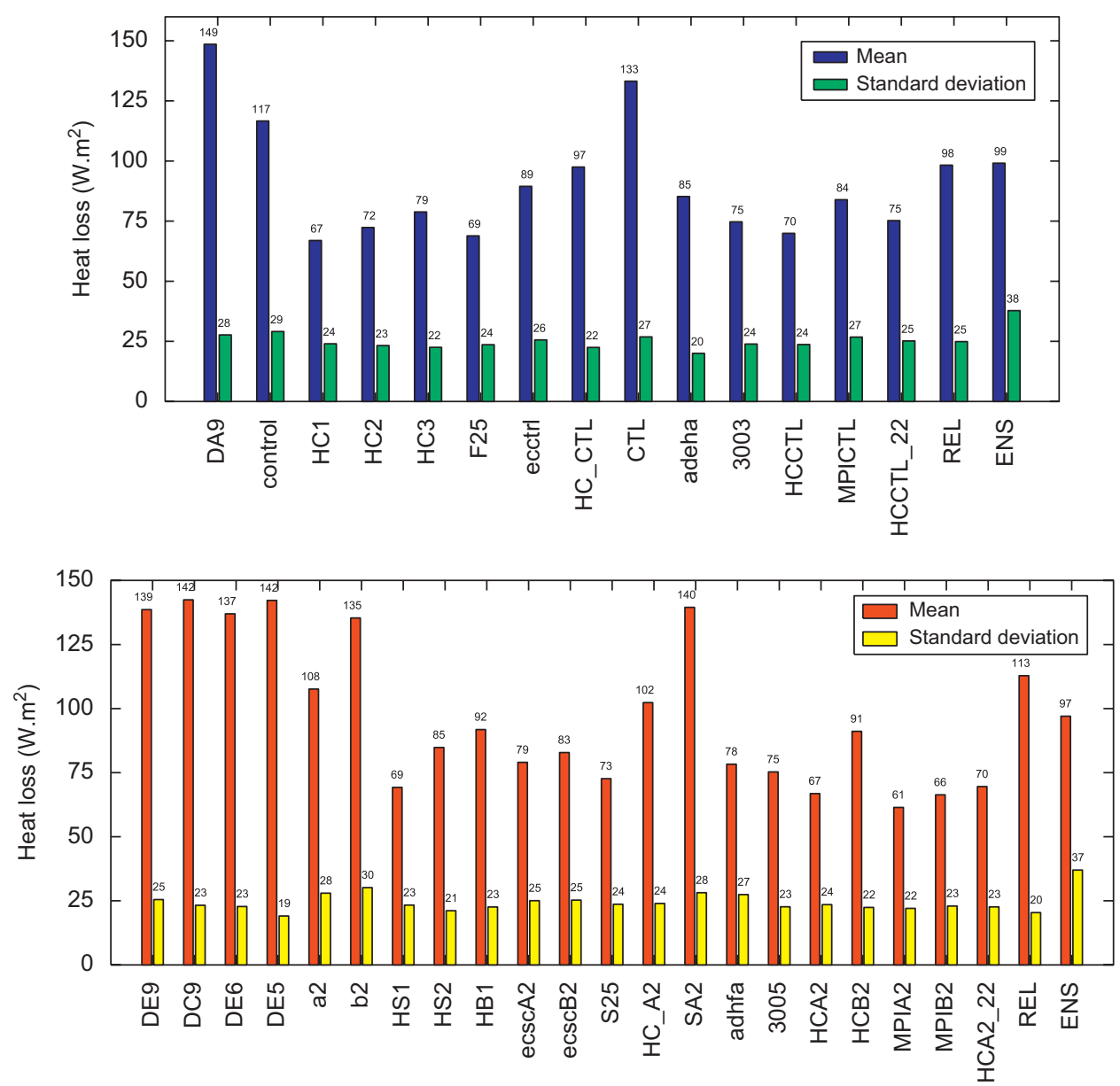

Fig. 11. Average and standard deviation of the mean December-March total heat loss over NWMS, $H L_{D J F M}\left(\mathrm{~W} \mathrm{~m}^{-2}\right.$ ), for each present-day climate simulation (top) and end of the XXIth century simulation (bottom) selected from the PRUDENCE project. REL corresponds to the heat loss of the ARCM ARPEGE-Climate simulations DA9 and DE9 corrected by the relaxation term, used to force the regional model SYMPHONIE (see Section 2.1). ENS corresponds to the 240-year ensemble mean formed by the eight present-day climate simulations for the eight ARCM (see Tables 5 and 6).

the 2-metre air temperature. SST values used in the ORCM simulation (see Section 2.1) is used for SST. The mean December-March total heat loss over NWMS, $H L_{D J F M}$, is obtained for each year of each simulation.

The average and standard deviation of $H L_{D J F M}$ are shown for both periods and for the different simulations in Fig. 11. REL is not a real simulation but represents the heat loss obtained when adding the relaxation heat flux to the heat flux of the DA9 and DE9 simulations (see Section 2.1). This heat loss is actually the one used to force the regional model SYMPHONIE. For both period, the ensemble mean ENS is the 240-year ensemble of the eight basis simulations of each institute (* in Tables 5 and 6$)$. In agreement with the variability of the temperature observed by Jacob et al. (2007), one observes an important variability of the heat loss among the ARCMs, both for the present and future periods, with a 2.3 factor between the weaker and stronger heat losses.

The relationships established in Section 5 are used to estimate the quantities of DW formed at the surface, exported and cascading for each year of each simulation. The results for REL actually correspond to results obtained in Section 5. The ORCM presented in Section 2.1 was not forced by all the different ARCMs compared here. The stratification is therefore assumed to be given by the simulation performed with the ORCM forced by ARPEGE-

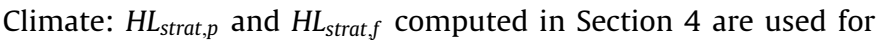
every simulations. The average and standard deviation of the resulting quantities for each simulation are presented in Figs. 12 and 13.
The different uncertainties are summarized and quantified in Table 8 . To quantify the uncertainty due to the choice of the ARCM, we compute the standard deviation of the results obtained for the different runs of the ensemble mean. For the other uncertainties, we compute

$$
\sqrt{\frac{\left.\sum_{\text {Institutes }}\left[\sum_{\text {runs }}(\text { value (Institute, run })-\overline{\text { value(Institute })}\right)^{2}\right]}{\left(\sum_{\text {Institutes }} \text { number of runs }\right)-1}}
$$

where $\overline{\text { value(Institute) }}$ is the average value obtained by an institute over different runs aimed at testing a given type of uncertainty.

\subsubsection{Impact of the choice of the ARCM}

The results show a strong sensitivity to the atmospheric ARCM, with two orders of magnitude between the most productive and least productive model in terms of DW (Figs. 12 and 13 and Table 8). For each run, and for both periods, the standard deviation is strong, of the same order as the average, showing that the strong interannual variability of the DW formation, export and cascading is reproduced by each model (Figs. 12 and 13). Considering that the ensemble mean was shown to perform better for the present period than the individual models (Jacob et al., 2007), the results obtained for ENS provide an estimate of the mean annual surface formed $\left(690 \mathrm{~km}^{3}\right)$, exported $\left(760 \mathrm{~km}^{3}\right)$ and cascading $\left(430 \mathrm{~km}^{3}\right)$ DW volume under present-day climate conditions, with standard deviations of the same order, showing the high interannual variability of these processes. These results 

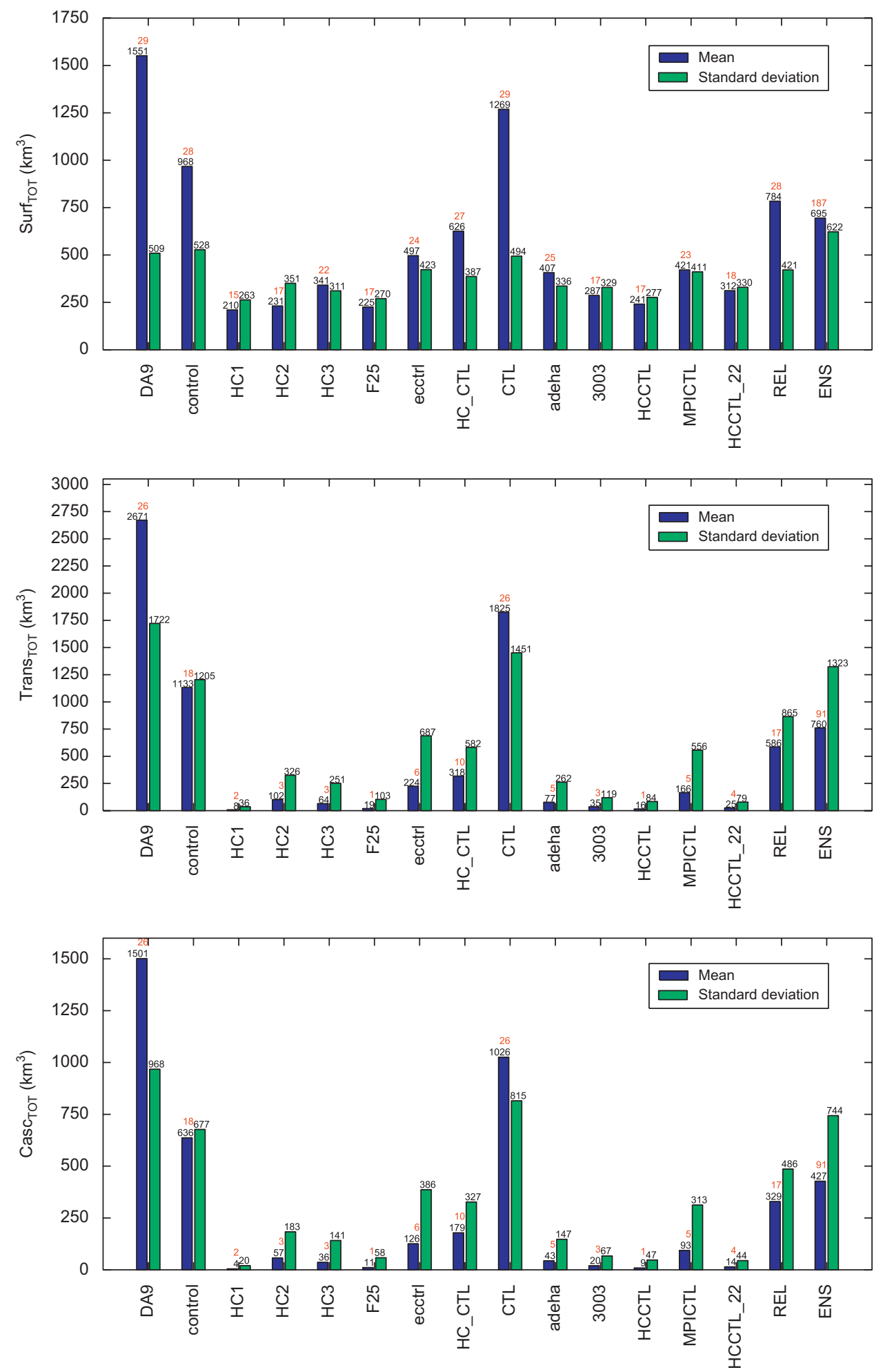

Fig. 12. Average and standard deviation of the DW formed at the surface $\operatorname{Surf}_{T O T}$, exported Trans $_{T O T}$, and cascading Casc $_{T O T}$ for each present-day climate simulation selected from the PRUDENCE project, for the REL set and for the mean ensemble ENS $\left(\mathrm{km}^{3}\right)$.

are close to the results obtained for REL, of, respectively, $788 \mathrm{~km}^{3}$, $597 \mathrm{~km}^{3}$ and $335 \mathrm{~km}^{3}$, corresponding to differences of $+14 \%,-21 \%$ and $-22 \%$ with the results obtained for ENS. The cascading volume obtained for the ensemble mean is also in the range of the observational data mentioned in Section 3.

Table 7 presents the ratio of $H L_{D J F M}$, Surf, Trans and Casc for each simulation of the 2071-2100 period compared with the corresponding simulation of the 1961-1990 period. For the A2 scenario, the change of the heat loss varies between $-17 \%$ (MPIA2) and $+18 \%$ (HS2), and is very small $(-2 \%)$ for the ensemble mean. For this scenario, the formation, export and cascading decrease for all the simulations, with decrease of cascading varying between $63 \%$ and $100 \%$. For the future period, the ensemble mean shows decreases of DW formation, export and 

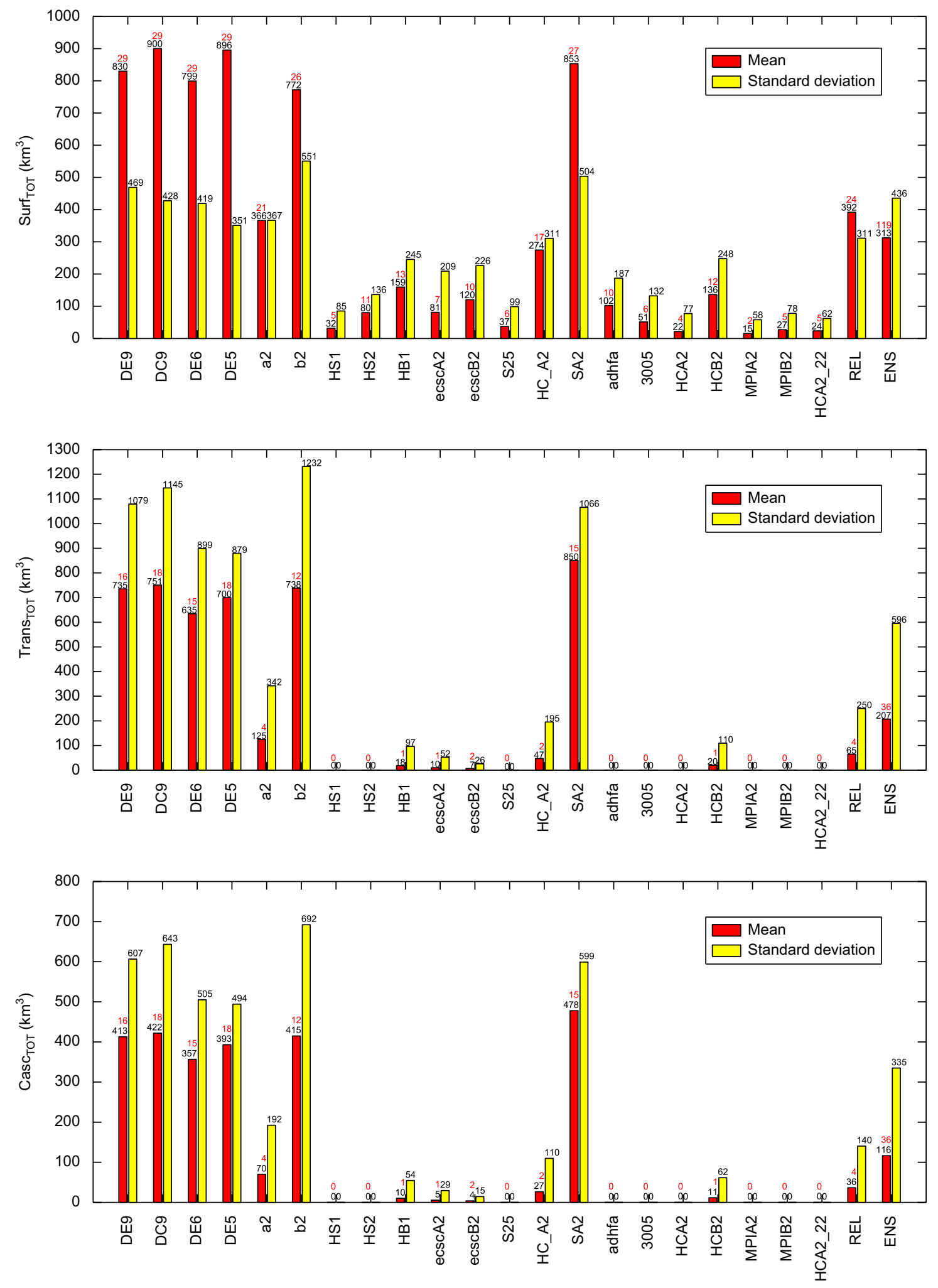

Fig. 13. Average and standard deviation of the DW formed at the surface Surf ${ }_{T O T}$, exported Trans ${ }_{T O T}$, and cascading Casc $_{T O T}$ for each XXIth century simulation selected from the PRUDENCE project, for the REL set and for the mean ensemble ENS $\left(\mathrm{km}^{3}\right)$.

cascading by of $65 \%, 74 \%$ and $73 \%$. In Section 5 , we obtained decreases of $50 \%, 90 \%$ and $89 \%$ for REL.

Examining the distribution of the quantities obtained with the ensemble mean (Fig. 14), surface formation occurs $75 \%$ of the years, and export and cascading occurs 65\% of the years in the present period. For the future period, these values decrease to $45 \%$ and $15 \%$. As explained in Section 5 , the fact that the mean export is higher than the mean surface formation under present-day climate (Fig. 14) is due to the years with the strongest heat losses. This happen also for some years of the future period, but only exceptionally, because of the stronger stratification. 
Table 7

Ratios of the winter heat loss $H L_{D J F M}$, and the yearly surface formation rate Surf, export Trans and cascading Casc between the 2071-2100 simulations and the corresponding 1961-2100 simulation

\begin{tabular}{llllll}
\hline Run name & HL $L_{D J F M}$ & Surf & Trans & Casc & Sc. \\
\hline DE9/DA9 & 0.93 & 0.54 & 0.28 & 0.28 & A2 \\
DC9/DA9 & 0.95 & 0.58 & 0.28 & 0.28 & B2 \\
DE6/DA9 & 0.92 & 0.52 & 0.24 & 0.24 & A2 \\
DE5/DA9 & 0.95 & 0.58 & 0.26 & 0.26 & B2 \\
a2/control & 0.92 & 0.38 & 0.11 & 0.11 & A2 \\
b2/control & 1.15 & 0.80 & 0.65 & 0.65 & B2 \\
HS1/HC1 & 1.03 & 0.15 & 0.00 & 0.00 & A2 \\
HS2/HC2 & 1.18 & 0.35 & 0.00 & 0.00 & A2 \\
HB1/HC1 & 1.37 & 0.76 & 2.25 & 2.50 & B2 \\
S25/F25 & 0.89 & 0.16 & 0.04 & 0.04 & A2 \\
ecscA2/ecctrl & 0.93 & 0.24 & 0.03 & 0.03 & A2 \\
ecsCB2/ecctrl & 1.06 & 0.16 & 0.00 & 0.00 & B2 \\
HC-A2/HC-CTL & 1.05 & 0.44 & 0.15 & 0.15 & A2 \\
SA2/CTL & 1.05 & 0.67 & 0.47 & 0.47 & A2 \\
adhfa/adeha & 0.92 & 0.25 & 0.00 & 0.00 & A2 \\
3005/3003 & 1.00 & 0.18 & 0.00 & 0.00 & A2 \\
HCA2/HCCTL & 0.96 & 0.09 & 0.00 & 0.00 & A2 \\
HCB2/HCCTL & 1.30 & 0.56 & 1.25 & 1.22 & B2 \\
MPIA2/MPICTL & 0.73 & 0.04 & 0.00 & 0.00 & A2 \\
MPIB2/MPICTL & 0.79 & 0.06 & 0.00 & 0.00 & B2 \\
HCA222/HCCTL22 & 0.93 & 0.08 & 0.00 & 0.00 & A2 \\
REL/REL & 1.15 & 0.50 & 0.11 & 0.11 & A2 \\
ENS /ENS & 0.98 & 0.45 & 0.26 & 0.27 & A2 \\
\hline
\end{tabular}

\subsubsection{Impact of the natural variability}

Three ensemble simulations performed by the DMI using the same model but changing only the initial conditions were available for the present period ( $\mathrm{HC} 1, \mathrm{HC} 2$ and $\mathrm{HC} 3$ ), and two for the future period (HS1, HS2). This enables to test the sensitivity of the model results to the climate variability. This does not have a very strong effect neither on the mean heat loss nor on its variability (see Fig. 11). The impact of the climate variability on the DW formed, exported and cascading in the present and future periods is negligible compared to the impact of the ARCM (Figs. 12 and 13 and Table 8).

\subsubsection{Impact of the spatial resolution of the ARCM}

The DMI and SMHI institutes used higher resolution models (HIRHAMh and RCAOh instead of HIRHAM and RCAO) to perform simulations for the present period (F25 and HCCTL22, to be compared with HC1,2,3 and HCCTL, see Table 5) and for the future period (S25, HCA222, to be compared with HS1,2 and HCA2, see Table 6). For both periods, the model resolution does not have a significant impact, neither on the heat loss nor on the DW quantities, compared to the impact of the ARCM (Figs. 12 and 13 and Table 8).

\subsubsection{Impact of the choice of the AOGCM}

Those two institutes also performed simulations with a different bounding AOGCMs (ECHAM4 instead of HadAM3H) for the present period (ecctrl and MPICTL) and for the future period (ecscA2 and MPIA2). For the present period, the impact on the DW quantities is more important than the impact of the resolution or the climate variability (Fig. 12 and Table 8): for both models, the AOGCM change results in an increase of the surface formation by a factor of 2 (for the DMI, the ecctrl run is compared with the mean of the $\mathrm{HC} 1, \mathrm{HC} 2$ and $\mathrm{HC} 3$ runs), and of the export and cascading by a factor of 10 for SMHI and 3.5 for DMI. For the future period, this impact is negligible. For both models, the impact of the choice of the AOGCM on the decrease of surface formation, export and cascading is negligible compared to the impact of the ARCM (Table 8).

\subsubsection{Impact of the choice of the scenario}

The CNRM, UCM, DMI and SMHI institutes performed simulations changing only the scenario from A2 to B2 (DC9, DE5, b2, HB1, ecscB2, HCB2 and MPIB2, to be compared with DE9, DE6, a2, HS1, escA2, HCA2 and MPIA2). The impact of the scenario varies among the simulations (Table 7), and the uncertainty due to the scenario is half the uncertainty due to the choice of the ARCM (Table 8). For DC9, DE5, and MPIB2, the decreases of the heat loss and of SW formation, export and cascading are comparable to the decrease obtained with the A2 scenario (DE9, DE6 and MPIA2). For ecscB2, the heat loss slightly increases $(+6 \%)$ whereas it slightly decreases in escA2 (-7\%), however, surface formation, export and cascading decreases are comparable. For the run b2 the heat loss increases by $15 \%$, whereas it decreases by $8 \%$ for a2, and the surface formation, export and cascading decrease for $\mathrm{b} 2$ is half that for $\mathrm{a} 2$. For HB1 and HCB2, the heat loss increases by more than $30 \%$, surface formation still decreases, but less than in the A2 simulations, and export and cascading even increase compared to the present period.

To summarize, the uncertainty in the modeling of DW formation, export and cascading is mostly due to the choice of the ARCM in the present and future periods and the scenarios in the future period. The model resolution, the choice of the forcing AOGCM and the natural variability of the climate have much weaker impacts, of at least one order of magnitude smaller (Table 8). The strong interannual variability of these processes is reproduced by every model. For the A2 scenario, DW formation, export and cascading decrease in all the simulations by at least $30 \%, 50 \%$ and $50 \%$, and in average, using the ENS mean, cascading is reduced by more than $70 \%$ at the end of the 21 st century. Globally, results obtained for ENS and for REL are quite similar, with a maximum difference of $20 \%$. Note that the uncertainty due to the vertical stratification is certainly important, but could not be assessed in the present study because of a lack of ORCM simulations due to the large numerical cost of such ORCM experiments: the ORCM used to force SYMPHONIE was only forced by one ARCM (see Section 2.1), and not by the other ARCMs compared in this section.

\section{Conclusion}

A regional oceanic circulation model was used in this study to examine the effects of interannual atmospheric variability and climate change on DW formation over, export from and cascading off the Gulf of Lions shelf. This model was forced at its lateral and surface boundaries by a 140 -year basin-scale simulation performed over the whole Mediterranean Sea. Seven years were selected in the present and future periods.

The analysis of the simulations for the selected years of the present period enabled to study the impact of interannual variability. Volumes of DW formed, exported and cascading are strongly related to the average heat loss during the DecemberMarch period. The interannual variability is strong for the three quantities, of the same order as the average values. Surface formation occurs every year, however, export and cascading occurs only for years colder than the average. The characteristics of DW formation and export (volumes, current velocity, density contrast, spatial variability) are in agreement with the observations.

For the selected years of the future period, surface formation still occurs, but for an equivalent heat loss, formed volume is smaller than for the present period. There is only one year with non-zero export and cascading, with volumes an order of magnitude smaller than volumes obtained for cold years of the present period. The decrease of DW formation and export is not due to a decrease of the winter heat loss, which actually slightly 

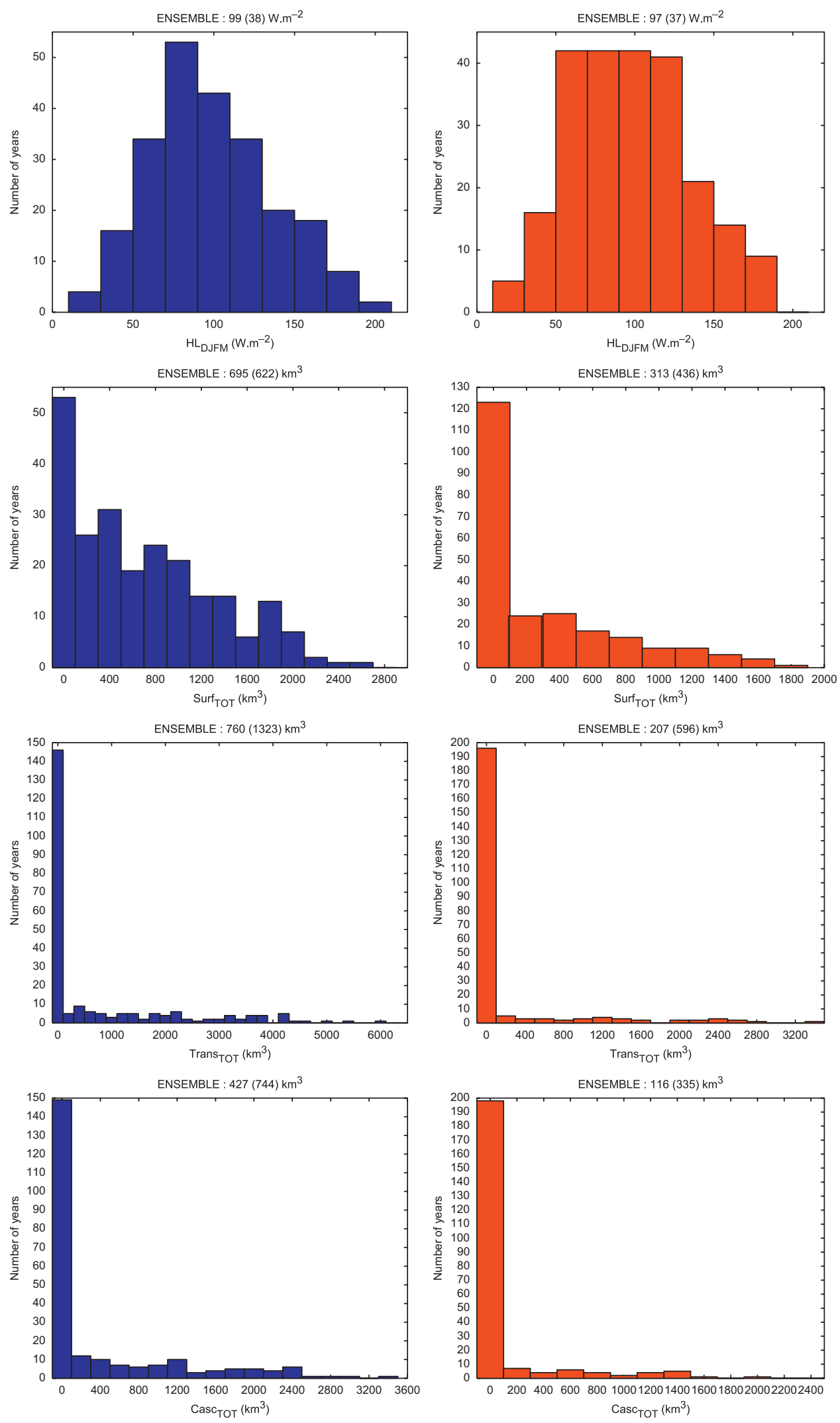

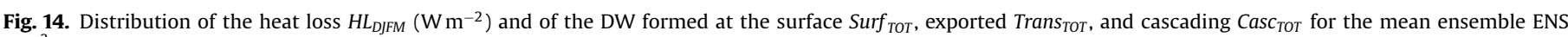
$\left(\mathrm{km}^{3}\right)$ under present-day climate conditions (left) and at the end of the XXIth century (right). The average and standard deviation are indicated.

increases between the present and future periods, but to the stronger stratification induced by the decrease of the annual buoyancy loss during the 21st century.
Results obtained for the selected years are extrapolated to the whole 30-year present and future periods using linear regression for the surface formation and non-linear regression for the export 
Table 8

Classification of the uncertainties

\begin{tabular}{lrrr}
\hline Uncertainty & Surf & Trans & CasC \\
\hline Present period & & & \\
$\quad$ ARCM & 512 & 1016 & 571 \\
Natural variability & 70 & 47 & 27 \\
Resolution & 30 & 6 & 4 \\
AOGCM & 138 & 107 & \\
& & & 427 \\
Value (ENS) & 695 & & \\
& & 338 & 190 \\
Future period & & 0 & 0 \\
RCM & 340 & 0 & 0 \\
Natural variability & 34 & 4 & 100 \\
Resolution & 2 & 178 & 116 \\
AOGCM & 20 & 207 & \\
Scenario & 132 & & \\
& & & \\
Value (ENS) & 313 & &
\end{tabular}

For the uncertainty due to the choice of the ARCM, standard deviation of the results obtained with the different runs of the ensemble mean. For the other uncertainties, $\left.\left.\sqrt{\sum_{\text {Institutes }}\left[\sum_{\text {runs }}(\text { value(Institute, run) }-\right.} \overline{\text { value(Institute) })}\right)^{2}\right] /\left(\sum_{\text {Institutes }}\right.$ number of runs); -1 with value(Institute) the average value obtained by an institute over different runs aimed at testing a given type of uncertainty. The values obtained for the ensemble mean are also indicated. Unit: $\mathrm{km}^{3}$.

and cascading. This statistic method enabled to establish a relationship between the volumes and the difference between the winter atmospheric heat loss and the heat loss necessary to increase the shelf water density up to the DW criteria. This latest heat loss is stronger in the future period compared to the present period $\left(\sim+30 \mathrm{Wm}^{-2}\right)$, because of the stronger stratification. For the present period, values of $\sim 800, \sim 600$ and $\sim 300 \mathrm{~km}^{3}$ are obtained for the 30-year average volume of water formed, exported and cascading. These values are reduced by, respectively, $50 \%, 90 \%$ and $90 \%$ by the end of the 21 st century.

Under the assumptions used in the present study, DW cascading practically disappears by the end of the 21st century. Such a change would have a tremendous impact on the deep ecosystems functioning, highly dependent on the quantity of nutrients provided by the DW coming from the shelf, and on the local carbon storage into the deep ocean.

Sensitivity tests to the choice of the DW density criteria, the parameters of the regional oceanic model, the water flux, the atmospheric forcing model and the scenario were performed. The uncertainty related to the forcing ARCM is the strongest, with two orders of magnitude between the most and least productive models in terms of DW, due to the high variability of the winter heat loss among the models. Nevertheless, the relative change between the present-day climate conditions and the 21st century does not change a lot among the forcing ARCMs. The scenario has also a strong impact, with differences between A2 and B2 scenarios varying a lot among the models.

Due to technical constraints, it was not possible to perform a 140-year simulation with the regional oceanic model. However, the time-computing costs are weaker and weaker due to technological advances, and it should be possible in the near future to perform 30 one-year simulations for the present period and for the future period. This method would give more precise information about the interannual variability and would enable to quantify more accurately the average annual rates.

It would also be very interesting to force the basin-scale ORCM using different ARCMs and scenarios to evaluate the impact of the stratification on our results. Such simulations should be available in the future thanks to the CIRCE project (http://www.bo.ingv.it/ circeip/). In the present study, due to a lack of ORCM simulations, the stratification was indeed considered independent on the ARCM. However, one can expect a rather "cold" or "warm" ARCM to produce different stratifications. This could be even more important for the future: the change of stratification induced by the evolution of the atmosphere during the 21st century would most certainly change depending on the ARCM and on the scenario. Note, however, that other climate change studies performed over the Mediterranean Sea (Thorpe and Bigg, 2000; Bozec, 2006) also predicted a weakening of the Mediterranean thermohaline circulation and a decrease of the surface density by the end of the 21st century, and therefore an increase of the stratification.

In this paper, we propose a downscaling strategy to investigate the regional impacts of short and long terms climate variability, going from global climate models to a basin ocean circulation model and finally to a high-resolution model. The enhancement of the stratification induced by climate change appears to have a considerable impact on the particular process studied here, i.e. the formation and fate of DW on the continental shelf. We focused our study on the Gulf of Lions, but this methodology could be used to study the effects of climate variability in other regions where cascading occurs (Ivanov et al., 2004; Durrieu de Madron et al., 2005). In particular, DW cascading occurring in the Adriactic and the Aegean seas could also be strongly affected by the increase of the stratification in the Mediterranean Sea. At a more global scale, the decrease of the stratification induced by the slowing of the Atlantic meridional overturning observed by Bryden et al. (2005) could affect the huge quantities of DW cascading in the North Atlantic and Artic continental shelves. Finally, this downscaling approach could be applied to examine the regional impact of climate change on other regional circulation processes (wind induced circulation, mesoscale processes etc.).

\section{Acknowledgments}

Data have been provided through the PRUDENCE data archive (prudence.dmi.dk), funded by the EU through Contract EVK2CT2001-00132.

\section{References}

Arakawa, A., Suarez, M.J., 1983. Vertical differencing of the primitive equations in sigma coordinates. Monthly Weather Review 111, 34-45.

Beckers, J., 1995. La Méditerranée occidentale: de la modélisation mathématique à la simulation numérique. $\mathrm{Ph} . \mathrm{D}$. Thesis, Université de Liège, Belgium.

Béthoux, J., Durrieu de Madron, X., Nyffeler, F., Tailliez, D., 2002. Deep water in the western Mediterranean: peculiar 1999 and 2000 characteristics, shelf formation hypothesis, variability since 1970 and geochemical inferences. Journal of Marine Systems 33-34, 117-131.

Blumberg, A.F., Mellor, G., 1987. A description of a three dimensional coastal circulation model. In: Heap, N. (Ed.), Three Dimensional Coastal Ocean Model. Bozec, A., 2006. La circulation thermohaline de la Mer Méditerranée sous des climats présent et futur. Ph.D. Thesis, Université Paris 6, Paris, France.

Bryden, H.L., Longworth, H.R., Cunningham1, S.A., 2005. Slowing of the Atlantic meridional overturning circulation at $25 \mathrm{~N}$. Nature 438, 655-657.

Canals, M., Puig, P., Durrieu de Madron, X., Heussner, S., Palanques, A., Fabres, J., 2006. Flushing submarine canyons. Nature 444, 354-357.

Christensen, J., Carter, T., Giorgi, F., 2002. Prudence employs new methods to assess European climate change. EOS Transactions-American Geophysical Union 83, 147.

Déqué, M., Rowell, D.P., Lüthi, D., Giorgi, F., Christensen, J.H., Rockel, B., Jacob, D., Kjellström, E., de Castro, M., van den Hurk, B., 2007. An intercomparison of regional climate simulations for Europe: assessing uncertainties in model projections. Climatic Change 81, 53-70.

Dufau-Julliand, C., Marsaleix, P., Petrenko, A., Dekeyser, I., 2004. Three-dimensional modeling of the Gulf of Lion's hydrodynamics (northwest Mediterranean) during January 1999 (MOOGLI3 Experiment) and late winter 1999: Western Mediterranean intermediate Water's (WIW's) formation and its cascading over the shelf break. Journal of Geophysical Research 109.

Durrieu de Madron, X., Zervakis, V., Theocharis, A., Georgopoulos, D., 2005. Comments on "Cascades of dense water around the world ocean". Progress in Oceanography 64, 83-90. 
Estournel, C., Durrieu de Madron, X., Marsaleix, P., Auclair, F., Julliand, C., Vehil, R. 2003. Observation and modelisation of the winter coastal oceanic circulation in the Gulf of Lions under wind conditions influenced by the continenta orography (FETCH experiment). Journal of Geophysical Research 108 (C3).

Estournel, C., Zervakis, V., Marsaleix, P., Papadopoulos, A., Auclair, F., Perivoliotis, L. Tragou, E., 2005. Dense water formation and cascading in the Gulf of Thermaikos (North Aegean) from observations and modelling. Continental Shelf Research 25, 2366-2386.

Gaudin, M., Berné, S., Jouanneau, J.-M., Palanques, A., Puig, P., Mulder, T., Cirac, P., Rabineau, M., Imbert, P., 2006. Massive sand beds attributed to deposition by dense water cascades in the Bourcart canyon head, Gulf of Lions (northwestern Mediterranean Sea). Marine Geology 234, 111-128.

Gibelin, A.-L., Déqué, M., 2003. Anthropogenic climate change over the Mediterranean region simulated by a global variable resolution model. Climate Dynamics 20, 327-339.

Heggelund, Y., Vikebo, F., Berntsen, J., Furnes, G., 2004. Hydrostatic and nonhydrostatic studies of gravitational adjustment over a slope. Continental Shelf Research 24, 2133-2148.

Herrmann, M., Somot, S., 2008. Relevance of ERA40 dynamical downscaling for modeling deep convection in the Mediterranean Sea. Geophysical Research Letters 35, L04607, doi:10.1029/2007GL032442.

Herrmann, M., Somot, S., Sevault, F., Estournel, C., Déqué, M., 2008. Modeling the deep convection in the Northwestern Mediterranean Sea using an eddypermitting and an eddy-resolving model: case study of winter 1986-87. Journal of Geophysical Research 113, C04011, doi:10.1029/2006JC003991.

Heussner, S., Durrieu de Madron, X., Calafat, A., Canals, M., Carbonne, J., Desault, N., Saragoni, G., 2006. Spatial and temporal variability of downward particle fluxe on a continental slope: lessons from an 8-yr experiment in the Gulf of Lions (NW Mediterranean). Marine Geology 234, 63-92.

Huthnance, J.M., 1995. Circulation, exchange and water masses at the ocean margin: the role of physical processes at the shelf edge. Progress in Oceanography 35 (4), 353-431.

IPCC, 2001. Climate change 2001. The scientific basis. Contribution of Working Group I to the Third Assessment Report of the IPCC. Cambridge University Press, Cambridge, UK.

Ivanov, V.V., Shapiro, G.I., Huthnance, J.M., Aleynik, D.L., Golovin, P.N., 2004. Cascades of dense water around the world ocean. Progress in Oceanography 60, 47-98.

Jacob, D., Bärring, L., Christensen, O.B., Christensen, J.H., de Castro, M., Déqué, M., Giorgi, F., Hagemann, S., Hirschi, M., Jones, R., Kjellström, E., Lenderink, G., Rockel, B., Sánchez, E., Schär, C., Seneviratne, S.I., Somot, S., van Ulden, A., den
Hurk, B.V., 2007. An inter-comparison of regional models for Europe: model performance in present-day climate. Climatic Change 81, 31-52.

Li, L., Bozec, A., Somot, S., Béranger, K., Bouruet-Aubertot, P., Sevault, F., Crépon, M. 2006. Regional atmospheric, marine processes and climate modelling. Mediterranean Climate Variability. Elsevier B.V. (Chapter 7).

Madec, G., Chartier, M., Crépon, M., 1991. The effect of thermohaline forcing variability on deep water formation in the western Mediterranean sea: a high resolution three dimensional numerical study. Dynamics of Atmospheres and Oceans 15, 301-332.

Marsaleix, P., Auclair, F., Estournel, C., 2006. Considerations on open boundary conditions for regional and coastal ocean models. Atmospheric and Oceanic Technology 23, 1603-1613.

Monaco, A., Biscaye, P., Soyer, J., Pocklington, R., Heussner, S., 1990. Particle fluxes and ecosystem response on a continental margin: the 1985-1988 Mediterranean ECOMARGE experiment. Continental Shelf Research 10 (9-11), 809-839.

Palanques, A., Durrieu de Madron, X., Puig, P., Fabres, J., Guillén, J., Calafat, A. Canals, M., Heussner, S., Bonnin, J., 2006. Suspended sediment fluxes and transport processes in the Gulf of Lions submarine canyons. The role of storms and dense water cascading. Marine Geology 234, 43-61.

Shapiro, G.I., Hill, A.E., 1997. Dynamics of dense water cascades at the shelf edge. Journal of Physical Oceanography 27, 2381-2394.

Simpson, J., 1987. Gravity Currents: In the Environment and in the Laboratory. Chichester.

Somot, S., Sevault, F., Déqué, M., 2006. Transient climate change scenario simulation of the Mediterranean Sea for the 21 st century using a high resolution ocean circulation model. Climate Dynamics 27 (7-9), 851-879.

Speer, K., Tziperman, E., 1992. Rates of water mass formation in the North Atlantic Ocean. Journal of Physical Oceanography 22, 93-104.

Thorpe, R., Bigg, G., 2000. Modelling the sensitivity of the Mediterranean outflow to anthropogenically forced climate change. Climate Dynamics 16, 355-368.

Tziperman, E., 1986. On the role of interior mixing and air-sea fluxes in determining the stratification and circulation of the oceans. Journal of Physical Oceanography 16, 680-693.

Ulses, C., Estournel, C., Bonnin, J., Durrieu de Madron, X., Marsaleix, P., 2008. Impact of storms and dense water cascading on shelf-slope exchanges in the Gulf of Lion (NW Mediterranean). Journal of Geophysical Research, in press.

Vörösmarty, C., Fekete, B., Tucker, B., 1996. Global river discharge database, RivDis. UNESCO, Paris, International Hydrological Program, Global Hydrological Archive and Analysis Systems.

Walin, G., 1982. On the relation between sea-surface heat flow and the thermal circulation in the ocean. Tellus 34,187-195. 